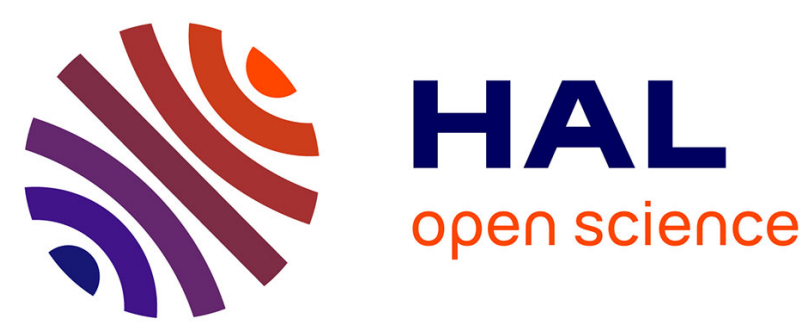

\title{
Interactions between amyloid precursor protein-like (APPL) and MAGUK scaffolding proteins contribute to appetitive long-term memory in Drosophila melanogaster
}

Bryon Silva, Christian Niehage, Marta Maglione, Bernard Hoflack, Stephan J. Sigrist, Thomas Wassmer, Alice Pavlowsky, Thomas Préat

\section{To cite this version:}

Bryon Silva, Christian Niehage, Marta Maglione, Bernard Hoflack, Stephan J. Sigrist, et al.. Interactions between amyloid precursor protein-like (APPL) and MAGUK scaffolding proteins contribute to appetitive long-term memory in Drosophila melanogaster. Journal of Neurogenetics, 2020, Future Perspectives of Neurogenetics - in honor of Troy D. Zars, 34 (1), pp.92-105. 10.1080/01677063.2020.1712597 . hal-02892323

\section{HAL Id: hal-02892323 \\ https://hal.science/hal-02892323}

Submitted on 29 Jul 2020

HAL is a multi-disciplinary open access archive for the deposit and dissemination of scientific research documents, whether they are published or not. The documents may come from teaching and research institutions in France or abroad, or from public or private research centers.
L'archive ouverte pluridisciplinaire HAL, est destinée au dépôt et à la diffusion de documents scientifiques de niveau recherche, publiés ou non, émanant des établissements d'enseignement et de recherche français ou étrangers, des laboratoires publics ou privés. 
Title

Interactions between Amyloid Precursor Protein-like (APPL) and MAGUK scaffolding proteins contribute to appetitive long-term memory in Drosophila melanogaster

Abbreviated title

APPL and MAGUKs interactions promote long-term memory

Author names

Bryon Silva ${ }^{1}$, Christian Niehage ${ }^{2}$, Marta Maglione ${ }^{3,4}$, Bernard Hoflack ${ }^{2}$, Stephan J. Sigrist ${ }^{3,4}$, Thomas Wassmer ${ }^{5}$, Alice Pavlowsky ${ }^{1, *}$, Thomas Preat ${ }^{1, *}$

Author affiliation

${ }^{1}$ Genes and Dynamics of Memory Systems, Brain Plasticity Unit, CNRS, ESPCI Paris, PSL Research University, 10 rue Vauquelin, 75005 Paris, France.

${ }^{2}$ Biotechnologisches Zentrum, TU-Dresden, Tatzberg 47-49, 01307 Dresden, Germany

${ }^{3}$ Institute for Biology/Genetics, Freie Universität Berlin, Takustr. 6, 14195 Berlin, Germany.

${ }^{4}$ NeuroCure Cluster of Excellence, Charité Universitätsmedizin, 10117 Berlin, Germany.

${ }^{5}$ Aston University, School of Life and Health Sciences, Aston Triangle, Birmingham, B4 7ET, United Kingdom.

* These authors contributed equally to this work.

Correspondence should be addressed to either Dr. Alice Pavlowsky or Dr. Thomas Preat, Genes and Dynamics of Memory Systems, Brain Plasticity Unit, Centre National de la 
Recherche Scientifique, ESPCI Paris, PSL Research University, 10 rue Vauquelin, 75005 Paris, France. E-mail: alice.pavlowsky@espci.fr or thomas.preat@espci.fr

\section{Author contributions}

Conceptualization: A.P., T.P., B.S., S.J.S., T.W., B.H.; investigation: B.S., C.N., M.M., T.W. and A.P; writing/original draft preparation: B.S. and A.P.; writing/review and editing: A.P., B.S., T.P., M.M., S.J.S, and T.W.; supervision: A.P., T.P., B.H., and S.J.S.; funding acquisition: T.P. and S.J.S.

\section{Conflict of Interest}

The authors declare no competing financial interests.

\section{Acknowledgments}

We thank the TRiP consortium at Harvard Medical School (NIH/NIGMS R01-GM084947) for providing transgenic RNAi fly stocks. We thank Aurélie Lampin-Saint-Amaux and Audrey Lombi for assistance with the behavior experiments. We are grateful to Dr. N. E. Reist for providing us the anti-Synaptotagmin 1 antibody. We thank the Core Facility BioSupraMol of the Freie Universität Berlin for the use of the Leica TCS SP8 system and for support. T.P. received grant support from the Fondation pour la Recherche Médicale (DEQ20140329540). B.S. is a recipient of the Graduate Program fellowship from the École des Neurosciences de Paris (ENP). 


\section{AbSTRACT}

Amyloid precursor protein (APP), the precursor of amyloid beta peptide, plays a central role in Alzheimer's disease (AD), a pathology characterized by memory decline and synaptic loss upon aging. Understanding the physiological role of APP is fundamental in deciphering the progression of $\mathrm{AD}$, and several studies suggest a synaptic function via protein-protein interactions. Nevertheless, it remains unclear whether and how these interactions contribute to memory. In Drosophila, we previously showed that APP-like (APPL), the fly APP homolog, is required for aversive associative memory in the olfactory memory center, the mushroom body (MB). In the present study, we show that APPL is required for appetitive long-term memory (LTM), another form of associative memory, in a specific neuronal subpopulation of the MB, the $\alpha^{\prime} / \beta$ ' Kenyon cells. Using a biochemical approach, we identify the synaptic MAGUK (membrane-associated guanylate kinase) proteins X11, CASK, Dlgh2 and Dlgh4 as interactants of the APP intracellular domain (AICD). Next, we show that the Drosophila homologs CASK and Dlg are also required for appetitive LTM in the $\alpha^{\prime} / \beta$, neurons. Finally, using a double RNAi approach, we demonstrate that genetic interactions between APPL and CASK, as well as between APPL and Dlg, are critical for appetitive LTM. In summary, our results suggest that APPL contributes to associative long-term memory through its interactions with the main synaptic scaffolding proteins CASK and Dlg. This function should be conserved across species. 


\section{INTRODUCTION}

$\mathrm{AD}$ is the principal neurodegenerative disorder affecting the elderly, and it is characterized by amyloid $\beta(\mathrm{A} \beta)$ deposition derived from proteolytic processing of amyloid precursor protein (APP) (Zheng and Koo, 2011). A pathological hallmark of AD is a progressive memory decline that correlates intimately with synaptic loss (Mucke and Selkoe, 2012). One of the main hypotheses for the cognitive deficits observed in $\mathrm{AD}$ is thus a dysfunction of synapses leading ultimately to synaptic loss and alteration of neural network activity (Styr and Slutsky, 2018). Therefore, it is essential to understand the physiological role of APP at the synapse. APP is a transmembrane protein expressed on both sides of the synapse (Wang et al., 2009). The APP extracellular domain can mediate dimerization across the synapse or interact with extracellular matrix components, growth factors and receptor-like proteins (Beher et al., 1996; Williamson et al., 1996; Rice et al., 2013). These interactions are involved in synapse stabilization during development and also in regulating synapse plasticity in mature neuronal networks (Montagna et al., 2017). APP can undergo two types of proteolytic processing, including the non-amyloidogenic pathway, which is initiated by $\alpha$-secretase and produces a secreted form of $\operatorname{APP}(\operatorname{sAPP} \alpha)$, and the amyloidogenic pathway, which successively involves $\beta$ - and then $\gamma$-secretase to release A $\beta$ peptide and an APP intracellular C-terminal domain (AICD) (Zheng and Koo, 2011). Although the manner in which proteolytic processing of APP and its derivatives interferes with neuronal physiology has been extensively studied (Palop and Mucke, 2010), little is known about the function of APP intra-cellular domain at the synapse or its synaptic partners.

Studies in mammals suggest that APP can interact via its intracellular domain with synaptic MAGUK proteins such as X11, CASK, or PSD-95 (Wang et al., 2009; Hoe et al., 2009). 
MAGUK proteins are involved in the assembly, maintenance and remodeling of the scaffolding in synaptic compartments (Kim and Sheng, 2004) mainly via regulation of the targeting of receptors and ion channels to the synapse (Tejedor et al., 1997; Ehrlich and Malinow, 2004). Therefore, understanding the interactions between APP and MAGUKs should help decipher the synaptic function of APP.

The three mammalian orthologs APP, APLP1 and APLP2 are partially functionally redundant (Shariati and De Strooper, 2013), whereas Drosophila expresses a single APP homolog named APP-like (APPL) (Luo et al., 1990) that has been implicated in olfactory memory (Goguel et al., 2011; Bourdet et al., 2015) and visual memory (Rieche et al., 2018). APPL is strongly expressed in the adult mushroom body (MB) (Torroja et al., 1996), the main olfactory memory center in insects (Heisenberg, 2003). We previously investigated the function of APPL in Drosophila aversive olfactory memory (Goguel et al., 2011; Bourdet et al., 2015; Preat and Goguel, 2016). However, whether the APP synaptic partners and their interactions might contribute to memory is still unexplored. Several MAGUK homologs in Drosophila have been identified such as dX11, CASK/Caki, and Discs-large (Dlg) (Oliva et al., 2012). Similar to its mammalian counterpart, dX11 binds APPL, and both are necessary for synaptic remodeling at the Drosophila neuromuscular junction (Ashley et al., 2005). Drosophila CASK regulates CaMKII activity (Hodge et al., 2006), interacts with dX11 (Butz et al., 1998) and is required in the MB for aversive memory (Malik et al., 2013). Mammalian Dlg1/SAP97, Dlg2/PSD-93, Dlg3/SAP102 and Dlg4/PSD-95 share similarities with the fly Dlg proteins DlgA and DlgS97 (Thomas et al., 2010), which are encoded by a single $d l g$ gene (Woods and Bryant, 1991). Both CASK and Dlg play key roles in neurotransmission, synaptogenesis and plasticity (Oliva et al., 2012). 
Here, we have aimed to decipher the role of APPL and its synaptic partners in appetitive olfactory memory. Additionally, to investigate the AICD interactome, we used a proteoliposome recruitment method (Pocha et al., 2011) and found that AICD interacts with the MAGUK synaptic proteins X11, CASK and Dlg. We then found in flies that APPL, CASK and Dlg are required specifically in the same neuronal subpopulation (the $\alpha^{\prime} / \beta^{\prime} \mathrm{KCs}$ ) for appetitive LTM. Finally, we used a double RNAi strategy to demonstrate that genetic interaction between APPL and MAGUKs is critical for appetitive LTM. To determine whether this memory deficit could be due to a major disorganization of the synaptic structure, we investigated both the pre-synaptic and the post-synaptic sites of $\mathrm{MB} \alpha^{\prime} / \beta^{\prime}$ neurons using confocal immuno-labelling of synaptic proteins.

\section{MATERIALS AND METHODS}

Drosophila stocks. Two fly stocks containing an RNAi construct against APPL were obtained from the Vienna Drosophila RNAi Center: $A P P L^{R N A i l}$ (KK102543, VDRC v108312) and $A P P L^{R N A i 2}$ (GD3170, VDRC v42673). RNAi lines for Dlg, Dlg ${ }^{R N A i l}$ (JF02287, BDSC 36771) and $\lg ^{R N A i 2}$ (JF01365, BDSC 25780), as well as for CASK, CASK ${ }^{R N A i l}$ (HMC03260 BDSC 51721) and $C A S K^{R N A i 2}$ (HMS00644, BDSC 32857), were obtained from the Bloomington Drosophila Stock Center (Indiana University, USA). The two RNAi constructs used to knockdown $d l g$ expression target both long and short isoform messages. The $A P P L ; C A S K^{R N A i}$ double RNAi line was constructed using the $A P P L^{R N A i 1}$ and $C A S K^{R N A i l}$ lines, whereas $A P P L ; D \lg ^{R N A i}$ was constructed with the $A P P L^{R N A i 1}$ and $D \lg ^{R N A i 1}$ lines. All mutants were outcrossed for at least five generations to flies carrying a Canton-S background. To restrict GAL4/UAS-mediated expression to the adult stage, we used the TARGET system (McGuire et al., 2003). We used the general MB driver tub-Gal80's ;238Y-Gal4 (tubGal80's $238 Y$ ) (Yang et al., 1995), the $\alpha / \beta$ neurons drivers tub-Gal80 ${ }^{\text {ts }} ;$ c739-Gal4 (tub- 


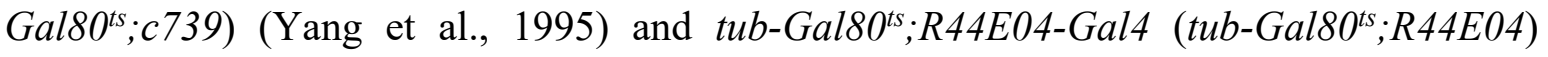
(Jenett et al., 2012), the $\alpha^{\prime} / \beta^{\prime}$ neurons driver tub-Gal80's; VT30604-Gal4 (tub-

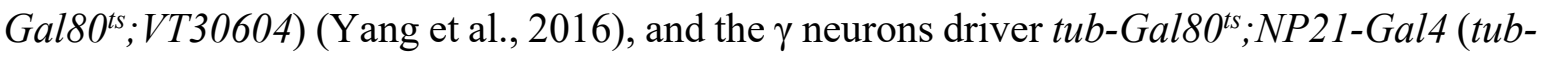
Gal80 $0^{t s}$;N21) (Ito et al., 1997). GAL4 activity was released by transferring adult flies to a $30.5^{\circ} \mathrm{C}$ incubator for 1 or 2 days, depending on the experiments. The non-induced control flies, in which RNAi expression is inhibited, were kept at $18^{\circ} \mathrm{C}$ (permissive temperature). After induction of a specific RNAi, the flies were kept at either $25^{\circ} \mathrm{C}$ (during the training period and memory test) or $18^{\circ} \mathrm{C}$ (24-hour storage period for the LTM experiment).

Behavioral training for appetitive memory. Briefly, groups of 40-60 2- to 4-day old male and female flies were food-deprived for either $16 \mathrm{~h}$ at $30.5^{\circ} \mathrm{C}$ (for induced flies) or $21 \mathrm{~h}$ at $25^{\circ} \mathrm{C}$ (for non-induced control flies) before conditioning in bottles containing filter paper soaked with water. Conditioning was performed by exposing the flies to one odor paired with a sucrose reward, with a subsequent exposure to a second odor in the absence of sucrose (Colomb et al., 2009). Odors used for conditioning were 3-octanol (95\% purity, SigmaAldrich) and 4-methylcyclohexanol (99\% purity, Sigma-Aldrich) at $0.360 \mathrm{mM}$ and 0.325 $\mathrm{mM}$, respectively and were diluted in paraffin oil (VWR International). After $2 \mathrm{~h}$ for STM or $24 \mathrm{~h}$ for LTM, the associative memory between the odor and the sugar was tested. For this, flies were exposed simultaneously to both odorants in a T-maze for 1 min under darkness. The performance index (PI) was calculated as the number of flies attracted to the conditioned stimulus $\left(\mathrm{CS}^{+}\right)$minus the number of flies attracted to the $\left(\mathrm{CS}^{-}\right)$, divided by the total number of flies in the experiment. This PI is multiplied by 100 to have a range between 100 and 100. A single memory performance index value is the average of the scores from two groups of flies of the same genotype trained with either octanol or methylcyclohexanol as the conditioning stimulus. 
Sugar response and olfactory acuity. To test for the sugar response or olfactory acuity, flies were kept at $30.5^{\circ} \mathrm{C}$ for 2 days and were then food-deprived for $16 \mathrm{~h}$. The sugar response was tested during $1 \mathrm{~min}$ in a T-maze. Briefly, the flies were exposed for 1 min under darkness in a T-maze to a tube completely covered with diluted sucrose $(0.2 \mathrm{M})$ on one side and an empty tube on the other side. For olfaction tests, flies were exposed simultaneously to both the odor and the paraffin oil alone for 1 min under darkness in a T-maze. Sugar and olfaction scores were calculated as for the memory scores (Colomb et al., 2009).

Proteo-liposome experiments. Protein recruitments and mass spectrometry were performed as established in Pocha et al. (2011) with the following modifications: $0.5 \mathrm{ml}$ of mouse brain cytosol (final concentration: $3 \mathrm{mg} / \mathrm{ml}$ ) was supplemented with $0.21 \mathrm{mM} \mathrm{GTP} \gamma \mathrm{S}$ and $28 \mu \mathrm{M}$ latrunculin B. The xcalibur.raw files were processed with MaxQuant, and the Perseus software from this package was used for analysis as previously described (Hubner et al., 2010). Briefly, LFQ intensities were logarithmized, and only proteins identified in every replicate of at least one of the samples were retained. Missing values were imputed by a normal distribution around the detection limit, and a modified t-test (SAM) was performed with a threshold value of 0.05 and a slope value of 1 . A detailed description of the method is presented in Niehage et al. (2014).

Quantitative PCR measurements. Flies were reared at $25^{\circ} \mathrm{C}$ throughout their development. Male flies carrying an RNAi construct were crossed with elav-Gal4 females (Brand and Perrimon, 1993) to assess their efficiency. Then, after eclosion, total RNA from 50 female heads was extracted using the RNeasy Plant Mini Kit (Qiagen). Whenever pan-neuronal expression of the RNAi during development was found to be lethal, elav-Gal4; tub-Gal80 ${ }^{\text {ts }}$ females were used instead of elav-Gal4 females for the cross and adults were placed at $30.5^{\circ} \mathrm{C}$ after eclosion for 3 days before being processed as the other flies. SuperScript III 
First-Strand kit (Life Technologies) and oligo(dT)20 were both used for retrotranscription. The tubulin gene alpha-Tub84B was used as referential cDNA as previously described (Turrel et al., 2016). Amplification was performed using the SYBR Green I Master mix (Roche) and a LightCycler 480 apparatus (Roche). All reactions were performed in triplicate using two different dilutions. A melting curve analysis was performed to assess the specificity of the amplified product, and expression relative to the reference was expressed as a ratio $\left(2^{-\Delta \mathrm{Cp}}\right.$, where $\mathrm{Cp}$ is the crossing point). The forward primer AGTACCAGGACATGCGCCTA and the reverse primer TCGAGTGCCTGAACAGAAGTC were used for APPL. The forward primer ACGCCTATCCCATACCACAT and the reverse primer TTCATCGTGCGAGACAAAGT were used for CASK. The forward primer AGGGATCCAAATCGAGGAG and the reverse primer CAATGGAAAAGCCCAATCC were used for Dlg.

Immunohistochemistry and confocal microscopy on whole mount Drosophila brains. Adult 4-5 days old male Drosophila brains, following 2 days RNAi induction, were dissected in ice-cold HL3 solution, fixed for $30 \mathrm{~min}$ in 4\% paraformaldehyde (PFA) in 1x phosphatebuffered saline (PBS), pH 7.2, at room temperature (RT), washed with $0.5 \%$ Triton X-100 in 1x PBS (PBT) and blocked in 10\% normal goat serum (NGS) in $0.5 \%$ PBT for $2 \mathrm{~h}$ at RT. The brains were incubated with primary antibodies together with 5\% NGS in $0.5 \%$ PBT for $48 \mathrm{~h}$ at $4^{\circ} \mathrm{C}$. The following primary antibodies were used: Dlg (1:100, mouse, catalog number: 4F3 anti- discs large, RRID: AB_528203, Developmental studies hybridoma bank (DSHB), University of Iowa, Iowa, USA), Drep2 (1:500, Rabbit, self-raised, Andlauer et al., 2014), BRP ${ }^{\mathrm{Nc} 82}$ (1:50 confocal, catalog number: nc82, RRID: AB_2314866, DSHB), Synaptotagmin 1 (1:500, Rabbit, a kind gift of Dr. N. E. Reist, Mackler et al., 2002). Brains were then washed in $0.5 \%$ PBT for $4 \mathrm{~h}$ ( $8 \times 30 \mathrm{~min}$ washing), followed by overnight 
incubation with secondary antibodies at $4^{\circ} \mathrm{C}$. The following secondary antibodies were used: Goat anti-Mouse Atto 647N (1:250 confocal, catalog number 15048, Active Motif, La Hulpe, Belgium) and Goat anti-Rabbit AF594 (1:250 confocal, Invitrogen, Carlsbad, USA). The brains were then washed for $3 \mathrm{~h}$ (6x 30min washing) with $0.5 \%$ PBT and mounted in VectaShield (Vector Laboratories, Burlingame, USA) on glass slides with high precision coverslips No. 1.5H (Carl Roth GmbH \& Co. KG, Karlsruhe, Germany) for confocal microscopy.

Conventional confocal images were acquired at constant $21^{\circ} \mathrm{C}$ with $\mathrm{TCS}$ SP8 confocal microscopes (Leica Microsystems, Wetzlar, Germany) equipped with the Leica LAS-X software, using either a $63 \mathrm{x}, 1.4 \mathrm{NA}$ oil or a $20 \mathrm{x}, 0.7 \mathrm{NA}$ oil objective. The lateral pixel size was set to values around $180 \mathrm{~nm} .1024$ x 1024 pixel resolution images were scanned at 400 $\mathrm{Hz}$ using 4x line averaging for stacks. Images were acquired with the same microscope/laser settings within the same scan session, alternating between different genotype groups to keep the conditions comparable. If a genotype comparison consisted of more than one dataset, values were normalized to the respective control group.

Image analysis. Confocal images were analyzed for mean pixel intensities using Amira 6.3.0 (FEI, Hillsboro, USA). The regions of interest (ROIs) were manually selected within the three-dimensional image stack using the Amira tool Segmentation Editor by interpolating manual selections between slices. Mean intensity values within the 3D mask for all channels were calculated separately using the Material Statistics tool. Values for both hemispheres were averaged per animal. To validate the specificity of knock down effects on BRP ${ }^{\mathrm{Nc} 82}$ and Syt1 intensities in the tip of alpha prime lobes, values retrieved in the alpha prime regions per each brain were normalized to values retrieved in the alpha lobes, as control region. Values were then normalized to controls. 
Experimental design and statistical analyses. Memory scores are displayed as mean $\pm \mathrm{SEM}$. Statistical analyses were performed by one-way ANOVA followed by the Newman-Keuls pairwise comparisons test (significance was set at $\mathrm{p} \leq 0.05$ ). ANOVA results are given as the value of the Fisher distribution $F_{(x, y)}$, where $x$ is number of degrees of freedom numerator and $y$ is the total number of degrees of freedom denominator. In addition, a two-tailed unpaired $t$-test was used to compare two conditions. Results from the unpaired $t$-test are given as the value $t_{x}$ of the $t$ distribution, where $x$ is number of degrees of freedom. Asterisks in each figure refer to post hoc comparison between the genotype of interest and the genotypic controls. All statistical studies were performed using GraphPad Prism 6.0 software (GraphPad Software; La Jolla, CA, USA). Data regarding confocal experiments were analyzed in GraphPad Prism (version 7.03, GraphPad, La Jolla, CA, USA) and statistics were done with a similar strategy as in Gupta et al. (Gupta et al., 2016). Differences between two groups were tested with the Mann Whitney U-test, differences between three groups were tested with the Kruskal-Wallis test. Significance threshold $\alpha$ was set to 0.05 . Only two-tailed $\mathrm{p}$ values less than 0.05 were considered significant. Sample size estimation was performed based on previous experience. Experiments were performed three times on different biological replicates, unless otherwise stated, $\mathrm{n}$ indicates the number of animals analyzed. Values are expressed as mean \pm SEM. All the data that were generated for this study are available and presented in the Supplementary Table 2.

\section{RESULTS}

\section{APPL expression in the MB is required for appetitive LTM}

To assess the potential contribution of APPL to appetitive memory, we used a previously described paradigm in which starved flies are first exposed to an odorant paired with a 
sucrose reward, followed by a second odorant in the absence of any sucrose presentation (Tempel et al., 1983; Colomb et al., 2009). Following this protocol, which consists of a single training cycle, STM and LTM are both formed (Colomb et al., 2009; Krashes and Waddell, 2008). To assess the role of APPL specifically in the adult MB, we drove the expression of a specific RNAi that targets APPL (using either $A P P L^{R N A i 1}$ or $A P P L^{R N A i 2}$ ) under the control of the MB 238Y-Gal4 driver, in combination with the ubiquitously expressed thermosensitive GAL4 inhibitor Gal80 (tub-Gal80 $\left.{ }^{t s}\right)$. We first confirmed that pan-neuronal expression of $\mathrm{APPL}^{\mathrm{RNAi}}$ using the elav driver reduced significantly the expression of APPL mRNA (Supplementary Figure 1A-B) (Goguel et al., 2011; Bourdet et al., 2015). Downregulation of APPL expression in the adult MB using $A P P L^{R N A i l}$ induced a strong LTM impairment (Figure 1A), whereas LTM was normal in the absence of RNAi induction (Figure 1B). Inhibition of APPL expression in the adult MB did not affect STM (Figure 1C). Finally, the sugar response and olfactory acuity controls were normal (Supplementary Figure 1C-E). To further confirm the specific role of APPL in appetitive LTM, we used a second nonoverlapping RNAi construct ( $A P P L^{R N A i 2}$ ) (Goguel et al., 2011). As observed with $A P P L^{R N A i l}$, flies expressing $A P P L^{R N A i 2}$ only in the adult MB presented a strong LTM impairment (Figure 1D), whereas flies exhibited normal LTM in the absence of thermal induction (Figure 1E). Similar to $A P P L^{R N A i 1}$, downregulation of APPL in the adult MB with $A P P L^{R N A i 2}$ did not affect STM (Figure 1F). Neither the sugar response nor the olfactory acuity was affected by $A P P L^{R N A i 2}$ expression in the adult MB (Supplementary Figure 1F-H). Therefore, our data show that APPL expression in the adult MB is required specifically for appetitive LTM.

\section{APP interacts with the mammalian synaptic proteins X11, CASK, Dlgh2 and Dlgh4}


In a previous study, we identified several elements of the mammalian PIKfyve complex as new interactants of the intracellular domain of APP, using an in vitro reconstitution system (Balklava et al., 2015). In this system, AICD is coupled to the surface of liposomes to mimic the organization of its intracellular domain in the native APP configuration together with a membrane context (Baust et al., 2006). These so-called 'proteo-liposomes' are then used to recruit interaction partners, which are then isolated and identified by mass spectrometry (Balklava et al., 2015; Baust et al., 2006; Pocha et al. 2011; Hubner et al., 2010). The interaction of AICD and the PIKfyve complex has been confirmed by other biochemical approaches, which validates the proteo-liposome system as a means to identify new AICD interactants (Balklava et al., 2015; Currinn et al., 2016). In addition to the PIKfyve complex and other proteins with various functions listed in Supplemental Table 1, the AICD interactome includes the MAGUKs Dlgh2 (NCBI: NM_016695) (Kim et al., 1996), Dlgh4 (NCBI: NM_007864) (Cho et al., 1992) and CASK (NCBI: NM_001284503) (Hata et al., 1996), in addition to the well-known AICD interacting proteins X11 $\alpha$ (NCBI: NM_177034) and X11ß (NCBI: NM_001291166) (Okamoto and Südhof, 1997) (Figure 2 and

\section{Supplemental Table 1).}

The existence of the APP/X11 $\alpha /$ CASK (Wang et al., 2009) and the CASK/X11 $\alpha / \mathrm{Dlg}$ (SAP97) protein complexes (Leonoudakis et al., 2004) have been described previously. Here, our results suggest the existence of a complex between APP and MAGUKs, which could be mediated by X11 $\alpha$ interaction. Given that X11, CASK, Dlgh2, and Dlgh4 are major components of the synapse and are involved in synaptic plasticity, and that the role of APP at the synapse is still elusive, we decided to focus on these identified APP interactants among all the others (Supplemental Table 1) and try to address the significance of these interactions using Drosophila. In Drosophila, the X11 $\alpha$ and X11 $\beta$ homologs (dX11L $\alpha$ and dX11L $\beta$, 
respectively) are involved in the cellular localization of axonal proteins such as APPL or FasII in the MB, and regulate APPL expression in different synaptic compartments; however, both proteins are functionally redundant in neurons (Gross et al., 2013). Thus, due to the potential functional redundancy of the X11 family proteins in Drosophila neurons, we decided to focus our behavioral dissection on the Drosophila homologs of the other identified synaptic MAGUK proteins.

\section{Expression of MAGUKs in the adult MB is required for appetitive memory}

CASK and Dlg, the Drosophila homologs of the identified mammalian interactants of APP, are expressed at the synapse and involved in synaptic plasticity, just like their mammalian counterparts (Hodge et al., 2006; Astorga et al., 2016; Oliva et al., 2012). However, their role in appetitive olfactory memory has never been determined. Therefore, before addressing the function of the APPL/MAGUKs interaction, it was necessary to evaluate their respective roles in appetitive long-term memory. We followed the same strategy as we used for APPL by downregulating the expression of each MAGUK gene specifically in the adult MB. Restricting the downregulation of CASK in the MB to the adult stage using the tubGal80 ${ }^{\text {ts }}$ 238Y-Gal4 driver induced a strong LTM impairment (Figure 3A), whereas LTM was normal in non-induced flies (Figure 3B). Sugar responses and olfactory acuity were not affected by $C A S K^{R N A i l}$ expression in the adult MB (Supplementary Figure 2A-C). To further confirm our results, we used a second non-overlapping RNAi, $C A S K^{R N A i 2}$. Expression of $C A S K^{R N A i 2}$ in the adult MB resulted in a strong LTM impairment (Figure 3C), whereas LTM was normal in the absence of thermal induction (Figure 3D). Sugar responses and olfactory acuity were not affected by $C A S K^{R N A i 2}$ expression in the adult MB (Supplementary Figure 2D-F). To assess that both CASK RNAi constructs efficiently reduced the CASK 
mRNA level, we used the pan-neuronal driver elav (Supplementary Figure 2G-H). We found that the efficiency of both RNAi constructs was similar in magnitude, with a reduction of $72 \%$ for $C A S K^{R N A i 1}$ and $70 \%$ for $C A S K^{R N A i 2}$, as compared to the controls. Altogether, the data indicate that CASK is required in the adult MB for appetitive LTM.

The other MAGUKs identified in the biochemical assay were Dlgh2/SAP97 and Dlgh4/PSD95, which have a unique ortholog in Drosophila Dlg (Thomas et al., 2010). Downregulation of Dlg in the adult MB resulted in a strong LTM impairment (Figure 4A), whereas LTM was normal in the absence of thermal induction (Figure 4B). In addition, neither the sugar response nor the olfactory acuity was affected by the downregulation of Dlg in the adult MB (Supplementary Figure 3A-C). These results were confirmed using a second Dlg RNAi $\left(D g^{R N A i 2}\right)$. Similarly, downregulation of Dlg in the adult MB using $D \lg ^{R N A i 2}$ led to a strong LTM defect (Figure 4C), whereas LTM was normal in the absence of any induction (Figure 4D). The sugar responses and olfactory acuity were not affected by downregulation of Dlg using $D \lg ^{R N A i 2}$ in the adult MB (Supplementary Figure 3D-F). Although we aimed to assess the efficiency of both RNAi constructs using qPCR, when we used the elav driver, Dlg $\ln ^{R A i l}$ expression resulted in lethality at the pupal stage. Thus, we restricted $D \lg ^{R N A i 1}$ expression to adulthood using the $t u b-G a l 80^{t s}$;elav-Gal4 driver. After three days of induction, these flies displayed a $24 \%$ reduction in Dlg mRNA expression as compared to the controls (Supplementary Figure 3G). Flies expressing $\lg ^{R N A i 2}$ under the control of the elav driver were viable and displayed a $77 \%$ reduction in the level of Dlg mRNA as compared to the controls (Supplementary Figure 3H). Taken together, our results demonstrate that Dlg is required in the adult $\mathrm{MB}$ for appetitive LTM.

Expression of either APPL or MAGUKs in the $\alpha^{\prime} \boldsymbol{\beta}^{\prime}$ KCs is required for appetitive LTM 
The MB is a symmetrical structure composed of approximately 4,000 Kenyon Cells (KCs) with three distinct neuronal subpopulations: the $\alpha / \beta, \alpha^{\prime} / \beta^{\prime}$, and $\gamma \mathrm{KCs}$ (Crittenden et al., 1998). Appetitive STM and LTM arise from parallel and independent memory traces located in two distinct subsets of MB neurons, respectively the $\gamma$ and $\alpha / \beta$ neurons (Trannoy et al., 2011). The third group of KCs, the $\alpha^{\prime} / \beta^{\prime}$ neurons, have been shown to be critical for consolidation of appetitive LTM (Krashes and Waddell, 2008). We hypothesized that if APPL, CASK and Dlg interactions are essential for appetitive memory, then they should be required in the same KC neuronal population for appetitive LTM. Therefore, we first sought to determine in which $\mathrm{KC}$ subpopulations APPL is required for appetitive LTM using specific Gal4 drivers combined with $t u b-G a l 80^{t s}$. Since the $\alpha / \beta \mathrm{KCs}$ are the site of appetitive LTM storage, we first investigated the effect of APPL downregulation in adult $\alpha / \beta$ KCs on LTM. After two days of induction, inhibition of APPL in adult $\alpha / \beta \mathrm{KCs}$ using the tubGal80 ${ }^{t s}$; R44E04-Gal4 driver did not impair LTM (Figure 5A). To confirm our results, we used a second specific $\alpha / \beta$ driver, tub-Gal80 ${ }^{\text {ts }}$; $739-G a l 4$. Similarly, after two days of induction the tub-Gal80 ${ }^{t s} ; c 739-G a l 4>A P P L^{R N A i l}$ flies displayed normal LTM (Figure 5B). It should be noted that both drivers have been successfully used in previous reports to drive the expression of transgenes in $\alpha / \beta \mathrm{KCs}$, resulting in memory defects (Bouzaiane et al., 2015; Turrel et al., 2017). Thus, our data surprisingly reveal that the $\alpha / \beta$ KCs cannot be the neuronal subpopulation in which APPL expression is required for appetitive LTM. We next examined whether APPL is required in the adult $\alpha^{\prime} / \beta^{\prime} \mathrm{KCs}$ for appetitive LTM, since this neuronal subpopulation has been shown to be critical for appetitive LTM consolidation (Krashes and Waddell, 2008). Downregulation of APPL in the adult $\alpha^{\prime} / \beta^{\prime} \mathrm{KCs}$ using the tubGal80 ${ }^{\text {ts }}$ VT30604-Gal4 driver induced a strong LTM impairment (Figure 5C), whereas LTM was normal in the absence of thermal induction (Figure 5D). Sugar responses and olfactory 
acuity were not affected by downregulation of APPL in the adult $\alpha^{\prime} / \beta^{\prime}$ KCs (Supplementary Figure 4A-C). Finally, LTM scores were normal when APPL was knocked down in the $\gamma$ KCs (Figure 5E), as expected since the $\gamma \mathrm{KCs}$ have not been implicated in appetitive LTM so far. Our data demonstrate that APPL is required specifically in the adult $\alpha^{\prime} / \beta^{\prime} \mathrm{KCs}$ for appetitive LTM, while it is dispensable in the $\alpha / \beta$ and $\gamma$ KCs. Since the $\alpha$ '/ $\beta$ ' KCs are required in appetitive LTM consolidation rather than retrieval, this suggests that APPL is likely to be required for consolidation of appetitive LTM.

We next sought to determine whether CASK and Dlg were also specifically required in the same KCs for LTM. Using the same tub-Gal80 ${ }^{\text {ts }}$;VT30604-Gal4 driver to control the expression of $C A S K^{R N A i l}$ in the adult $\alpha^{\prime} / \beta^{\prime} \mathrm{KCs}$, we observed a strong LTM impairment (Figure 5F), whereas LTM was normal in the absence of thermal induction (Figure 5G). Sugar responses and olfactory acuity were normal in flies expressing $C A S K^{R N A i l}$ in the adult $\alpha^{\prime} / \beta$ ' KCs (Supplementary Figure 4D-F). Similarly, we observed a LTM impairment when using the $t u b-G a l 80^{t s}$;VT30604-Gal4 driver to control the expression of Dlg $g^{R N A i l}$ in the adult $\alpha^{\prime} / \beta$ ' KCs (Figure 5H), whereas LTM was normal in the absence of thermal induction (Figure 5I). Sugar responses and olfactory acuity were unaffected by $D \lg ^{R N A i l}$ expression in the $\alpha^{\prime} / \beta^{\prime}$ KCs (Supplementary Figure 4G-I). Thus, these data demonstrate that APPL, CASK and Dlg are all specifically required in the adult $\alpha^{\prime} / \beta^{\prime} \mathrm{KCs}$ for appetitive LTM.

\section{Genetic interaction between APPL and MAGUK proteins in the $\alpha$ '/ $\beta$ ' neurons is critical}

\section{for appetitive LTM}

To address the question of the physiological importance of the genetic interactions between APPL and either CASK or Dlg, we produced two Drosophila lines carrying two RNAi constructs that included $A P P L^{R N A i l}$ and either $C A S K^{R N A i l}$ or $D \lg ^{R N A i l}$. Since the insertion of 
two UAS transgenes can reduce their expression efficiency, we first assessed whether the presence of two UAS-RNAi constructs had any effect on the efficiency of each RNAi. Using the elav driver to control the expression of the double RNAi $A P P L^{R N A i l} ; C A S K^{R N A i l}$, we observed a strong reduction in the mRNA levels of APPL (91\%) and CASK (64\%) as compared to the controls (Supplemental Figure 5A and 5B respectively). Moreover, this reduction was similar in magnitude to that of the single constructs for $A P P L^{R N A i l}$ and $C A S K^{R N A i 1}$ (Supplemental Figure 5A-B). Since $D \lg ^{R N A i 1}$ expression with the elav driver resulted in lethality at the pupal stage, we used the tub-Gal80ts; elav-Gal4 driver to control the expression of the double RNAi $A P P L^{R N A i 1} ; D \lg ^{R N A i 1}$. In induced flies we observed a significant reduction in the mRNA levels of APPL (33\%) and Dlg (16\%) as compared to the controls (Supplemental Figure 5C and 5D respectively). These effects are similar in magnitude to the single RNAi conditions or even stronger in the case of APPL mRNA level (Supplemental Figure 5C-D). Thus, in the two double RNAi lines, the presence of the two UAS-RNAi constructs did not negatively affect the efficiency of downregulating either target mRNA.

To test for a possible genetic interaction between APPL and each of the MAGUK proteins, we assumed that the behavioral phenotype would be aggravated when APPL is downregulated in combination with either CASK or Dlg downregulation. In order to foster a condition where the expression of a single APPL, CASK or Dlg RNAi construct does not affect LTM, we modified our regular induction protocol by reducing the induction time from two days to one day. Under these conditions, we found that the single RNAi expression of $A P P L^{R N A i 1}$ or $C A S K^{R N A i l}$ in the adult $\alpha^{\prime} / \beta^{\prime} \mathrm{KCs}$ did not affect LTM (Figure 6A). Strikingly, the expression of $A P P L^{R N A i l} ; C A S K^{R N A i l}$ in the adult $\alpha^{\prime} / \beta^{\prime}$ KCs resulted in a strong LTM impairment (Figure 6A). As expected, LTM was normal when RNAi expression was not 
induced (Figure 6B). The sugar responses and olfactory acuity were normal in these flies expressing $A P P L^{R N A i l} ; C A S K^{R N A i l}$ in the adult $\alpha^{\prime} / \beta^{\prime}$ KCs (Supplemental Figure 5E-G ). This genetic interaction data demonstrates the combined requirement of APPL and CASK in the $\alpha^{\prime} / \beta^{\prime}$ KCs specifically for appetitive LTM.

To assess the potential contribution of the interaction between APPL and Dlg, we followed a similar approach. After one day of induction, the expression of a single RNAi construct targeted against either APPL or Dlg did not affect LTM (Figure 6C), whereas expression of $A P P L^{R N A i l} ; D l g^{R N A i 1}$ in the adult $\alpha^{\prime} / \beta^{\prime}$ KCs induced a strong LTM defect (Figure 6C). LTM was normal in the absence of any thermal induction (Figure 6D). The sugar response and olfactory acuity (Supplemental Figure 5H-J) were normal in these flies expressing $A P P L^{R N A i 1} ; D \lg ^{R N A i 1}$ in the adult $\alpha^{\prime} / \beta^{\prime} \mathrm{KCs}$. Thus, our genetic interaction experiments show that APPL and Dlg are synergistically required to specifically sustain appetitive LTM in the adult $\alpha^{\prime} / \beta^{\prime} \mathrm{KCs}$.

Since the AICD was previously described to possess some gene regulation properties (Slomnicki and Lesniak, 2008), we sought to assess whether or not the genetic interaction could be due to a transcriptional effect of APPL on CASK or Dlg. As presented in Supplemental Figure 6A-D, the reduction in APPL expression by either $A P P L^{R N A i l}$ or $A P P L^{R N A i 2}$ did not affect the mRNA levels of CASK or Dlg. Similarly, reduction of CASK or Dlg expression by RNAi-mediated silencing did not reduce the APPL mRNA level (Supplemental Figure 6E-G). Altogether, these results demonstrate that the genetic interactions between APP and the MAGUK proteins CASK and Dlg are not due to a transcriptional effect of AICD on Dlg and CASK genes but likely rely on protein-protein interactions as suggested by the AICD interactome experiment (Figure 2). 


\section{Downregulation of APPL and its synaptic MAGUKs partners in the adult $\alpha^{\prime} / \beta^{\prime}$ KC do not induce major synaptic disorganization.}

It is widely accepted that synapses are the basic units for memory storage through modification of synaptic strength (Poo et al., 2016). Alterations of the synaptic structure could be a molecular explanation to memory defect. To test this hypothesis, we investigated, in our two double knockdown contexts examined here, both the pre-synaptic and the postsynaptic sites of $\mathrm{MB} \alpha^{\prime} / \beta$ ' neurons using confocal imaging of immuno-labelled synaptic proteins known to be master structural organizers of each compartment. At the pre-synaptic site, Bruchpilot (Brp) and Synaptotagmin 1 are key proteins of the active zone, the site of synaptic vesicle recruitment, docking, priming and calcium-triggering fusion (Kittel et al. 2006, Walter et al., 2018). Synaptotagmin 1 is a synaptic vesicle associated Calcium-binding protein which acts as a calcium sensor for calcium-triggered synaptic vesicle exocytosis (Südhof, 2004) whereas Bruchpilot is an orthogonal scaffold protein of the active zone that keeps synaptic vesicles and voltage-gated calcium channels, the fusion trigger, in close proximity (Kittel et al. 2006, Fulterer et al. 2018). Expression of either the double $A P P L^{R N A i l} ; C_{A S K}^{R N A i l}$ construct or the double $A P P L^{R N A i l} ; \lg ^{R N A i l}$ construct in the $\alpha^{\prime} / \beta^{\prime}$ neurons during 2-days did not affect the Bruchpilot (BRP ${ }^{\mathrm{Nc} 82}$ ) or the Synaptotagmin 1(Syt1) labeling intensity in the tip of the $\alpha^{\prime}$ lobes normalized to $\alpha$ lobes as compared to the $t u b$ Gal80 ${ }^{t s} ; V T 30604 /+$ control (Fig 7. A-C). Thus, down-regulation of either of these genes does not significantly alter the overall Bruchpilot and Synaptotagmin 1 levels over the KC synapses, even if all the three proteins have been described as present in the axonal compartment of neurons (Torroja et al., 1996, Astorga et al., 2016, Chen and Featherstone, 2011). Thus, the memory defect observed previously cannot be directly linked to gross deficit in the synaptic vesicle or active zone organization but likely rely on more subtle mechanisms, 
as for example decreased plasticity of only a confined subset of synapses after knockdown of APPL/CASK. To also investigate the post-synaptic compartment of the $\alpha^{\prime} / \beta^{\prime}$ neurons, we performed confocal imaging of the calyx region of the MB using the post-synaptic proteins Dlg, the well-known scaffold protein previously described, and Drep2 which is required for metabotropic receptor coupling with regulation of local translation and highly expressed at the post-synaptic densities of KC calyx (Andlauer et al. 2014; Fig7, D-I). However, since the dendrites of the $\alpha^{\prime} / \beta^{\prime}, \alpha / \beta$ and $\gamma$ neurons are intermingled in the calyx and that there is no specific marker of $\alpha^{\prime} / \beta^{\prime}$ dendrites available, we could not specifically quantify the molecular status of the $\alpha^{\prime} / \beta^{\prime}$ neurons post-synapses. As expected, expression of the double $A P P L^{R N A i 1} ; D l g^{R N A i l}$ construct in the $\alpha^{\prime} / \beta^{\prime}$ neurons during 2-days reduced significantly Dlg intensity in the calyx region (Fig 7, G-H) as compared to the $t u b-G a l 80^{t s}$; VT30604/+ control confirming again that our RNAi strategy for Dlg knock-down is efficient. Notably, we found that Drep2 was not affected by down-regulation of both APPL and Dlg in the adult $\alpha^{\prime} / \beta^{\prime}$ neurons (Fig 7, I). These results suggest that despite the reduction of Dlg presence at the synapse, other post-synaptic scaffold proteins are not affected. Expression of the double $A P P L^{R N A i l} ; C A S K^{R N A i l}$ construct in the $\alpha^{\prime} / \beta^{\prime}$ neurons during 2 -days affected neither Dlg intensity nor Drep2 intensity in the calyx region (Fig 7, D-F) when compared to the tubGal80 ${ }^{t s}$;VT30604/+ controls. These results suggest that the main organization of the postsynaptic sites of $\alpha^{\prime} / \beta^{\prime}$ neurons are not affected by down-regulation of either CASK or APPL. Altogether, these experiments suggest that down-regulation of APPL and MAGUKs in the adult $\alpha^{\prime} / \beta^{\prime}$ neurons do not induce major disorganization of either the pre or post-synaptic compartment despite of the efficient reduction of protein level upon knock-down, at least for Dlg. 


\section{DISCUSSION}

We previously showed that APPL is required in the $\alpha / \beta$ and $\gamma$ KCs for aversive LTM (Goguel et al., 2011). More recently, we demonstrated that APPL is required for aversive LTM and MTM in the DPM neurons (Turrel et al., 2017), a pair of serotonergic and GABAergic neurons that project to each of the MB lobes, where they connect both pre- and postsynaptically to the KCs (Lee et al., 2011; Haynes et al., 2015). Here, we have reported that APPL is also required in another form of long-lasting protein synthesis-dependent memory, appetitive LTM, albeit surprisingly in a different subpopulation of $\mathrm{KCs}$, the $\alpha^{\prime} / \beta^{\prime}$ neurons. The requirement of APPL in $\alpha^{\prime} / \beta^{\prime}$ but not in the other KCs for appetitive LTM suggests that it has a specific role in appetitive LTM consolidation, as consolidation of appetitive LTM requires synaptic neurotransmission from $\alpha^{\prime} / \beta^{\prime}$ (Krashes and Waddell, 2008; Trannoy et al., 2011). Interestingly, recurrent activity of the $\alpha^{\prime} / \beta^{\prime}$-DPM loop has been described as necessary to consolidate appetitive memories (Krashes et al., 2007; Krashes and Waddell, 2008), with LTM eventually being stored in the $\alpha / \beta$ neurons (Krashes and Waddell 2008; Trannoy et al., 2011). An involvement of APPL in memory consolidation may rely on transsynaptic APPL interactions and may also contribute to the molecular support of the $\alpha^{\prime} / \beta^{\prime}$-DPM loop. Eventually such a role of APPL in memory consolidation through transsynaptic interaction would be consistent with published research in mammals. Indeed, at the cellular level APP is expressed in pre- and postsynaptic compartments and can form trans-dimers that have been suggested as necessary for synaptic function (Wang et al., 2009). In addition, perturbation of APP function by intraventricular infusion of an antibody against APP induced memory impairments only when it was performed during the memory consolidation phase of a passive avoidance task (Doyle et al., 1990). As shown for other synaptic cell adhesion molecules, the regulation of APP expression at the neuronal membrane 
is critical for hippocampal-dependent memory consolidation in the dentate gyrus, suggesting a potential involvement of APP in synaptic remodeling (Conboy et al., 2005). Altogether, the present findings combined with research on mammalian models suggest that APP might have a conserved function across species in memory consolidation processes via transsynaptic interactions.

Here, we have shown that in addition to the previously known X11 proteins, the intracellular domain of APP interacts with other scaffolding proteins (CASK, Dlg2/PSD-93 and Dlg4/PSD-95). However, it is not clear whether these proteins interact directly with APP or if their interactions are mediated by the X11 adaptor proteins, as it has been described for CASK (Wang et al., 2009). Our study demonstrates that the Drosophila homologs of these proteins, i.e. CASK and Dlg, are required in the same neuronal subpopulation as APPL for proper long-term memory. Several arguments in favor of an APPL/X11/CASK/Dlg macromolecular complex can be found in previous studies on mammals or Drosophila. In the Drosophila visual system, the MAGUK complex Lin-7/Dlg/CASK is involved in synaptic stabilization and the interaction between CASK and Dlg proteins has been described as direct (Soukup et al., 2013). The role of CASK in the recruitment of Dlg1 to the membrane in various cell types has been confirmed in a recent study showing that the $\mathrm{N}$-terminal domain of Dlg1 is critical for its interaction with CASK (Porter et al., 2019). In mammals, the existence of the APP/X11/CASK ternary complex has also been documented (Wang et al., 2009), and the regulation of neuronal excitability through potassium Kir2 channels involves a macromolecular complex consisting of Lin-7/SAP97/CASK/X11 (Leonoudakis et al., 2004). Altogether these studies demonstrate that the interaction between the Dlg, CASK and $\mathrm{X} 11$ proteins is both possible and functionally relevant for neuronal physiology. Finally, CASK binds to the Dlg protein SAP97 in mammalian hippocampal neurons to regulate its 
conformation state and thus its role in glutamate receptor trafficking and insertion at the synapse (Lin et al., 2013). Thus, the existence of the APPL/X11/CASK/Dlg macromolecular complex is consistent with previously published reports, and even if here we only demonstrate the genetic interaction between APPL, CASK and Dlg for appetitive LTM, it is likely that such a complex exists in Drosophila $\alpha^{\prime} / \beta^{\prime}$ MB neurons. Complementary studies using genetic tools to impair the interactions between these proteins such as overexpression of an interfering peptide corresponding to the N-terminus of Dlg as in Porter et al. 2019, could bring the confirmation that protein-protein interactions between APPL/X11/CASK/ Dlg are required for appetitive LTM via synaptic stabilization of the $\alpha^{\prime} / \beta^{\prime}$ neurons. In the present study, we looked at synaptic organization using confocal microscopy and immunolabeling of either pre-synaptic proteins of the active zone or post-synaptic scaffold proteins. The levels of the analyzed pre- or post-synaptic proteins were not affected by the concomitant knock down of APPL and MAGUKs in the adult $\alpha^{\prime} / \beta^{\prime}$ neurons, indicating no obvious alterations in MB synaptic structure. We note that as expected we observed a significant decrease in Dlg levels in the MB calyx upon knock down of APPL;Dlg in $\alpha^{\prime} / \beta^{\prime}$ neurons, demonstrating the efficacy of the knock down. To determine the requirement of these proteins for pre- or post-synaptic subtle organization, higher-resolution imaging studies would be required. However, such modification might be difficult to observe if, as suggested by the role of CASK and Dlg proteins, the APPL/X11/CASK/Dlg macromolecular complex is involved in synaptic stabilization specifically when synapses are modified during plastic event, and not as a basal mechanism for synaptic organization and formation as described for APPL and FasII interactions at the NJM (Torroja et al., 1999, Rieche et al., 2018). Interestingly, the Dlg protein SAP97 is involved in trafficking the $\alpha$-secretase ADAM10 to the synapse through direct interaction, consequently regulating APP processing and the 
production of the neurotrophic and neuroprotective secreted-APP $\alpha$ fragment (Marcello et al., 2007). We have previously shown in Drosophila that a secreted fragment of APPL is involved in aversive memory, as well as kuzbanian, the Drosophila homolog of ADAM10 (Bourdet et al., 2015). Therefore, an APPL/X11/CASK/Dlg supramolecular complex could also be involved in recruiting $\alpha$-secretase at the synaptic site as well as generating sAPP $\alpha$. The subcellular localization of APP and MAGUK interactions in the KCs is still an open question. In Drosophila, Dlg and CASK are known to be present at both the pre- and postsynaptic compartments (Thomas et al., 2010; Chen and Featherstone, 2011; Astorga et al., 2016). However, APPL has been described mainly in the neuropil of KCs (Torroja et al., 1996). Furthermore, the APPL binding protein X11 targets APPL to the axonal compartments and excludes it from MB dendrites via endocytosis (Gross et al., 2013). These data suggest that the APPL-MAGUKs complexes would be localized in the $\alpha^{\prime} / \beta^{\prime} \mathrm{KC}$ axonal compartment (i.e. the $\alpha^{\prime} / \beta^{\prime}$ lobes), which is importantly also the site of the $\mathrm{DPM} / \mathrm{KC}$ dialog for appetitive LTM consolidation.

In conclusion, the work reported here highlights a novel role of APPL and its synaptic partners in appetitive long-term memory in Drosophila. We have demonstrated that genetic interactions between APPL and the MAGUKs is critical for appetitive LTM in the $\alpha^{\prime} / \beta^{\prime} \mathrm{KCs}$, a neuronal sub-population known to be involved in the consolidation of appetitive LTM (Krashes and Waddell, 2008). Finally, we propose a model in which the role of the interactions between APPL, CASK and Dlg might be the synaptic stabilization of the $\alpha^{\prime} / \beta^{\prime}-$ DPM loop through transsynaptic interactions. 


\section{REFERENCES}

Andlauer TFM, Scholz-Kornehl S, Tian R, Kirchner M, Babikir HA, Depner H, Loll B, Quentin C, Gupta VK, Holt MG, Dipt S, Cressy M, Wahl MC, Fiala A, Selbach M, Schwärzel M, Sigrist SJ (2014) Drep-2 is a novel synaptic protein important for learning and memory. Elife 3:1-24.

Ashley J, Packard M, Ataman B, Budnik V (2005) Fasciclin II Signals New Synapse Formation through Amyloid Precursor Protein and the Scaffolding Protein dX11/Mint. J Neurosci 25:5943-5955.

Astorga C, Jorquera RA, Ramírez M, Kohler A, López E, Delgado R, Córdova A, Olguín P, Sierralta J (2016) Presynaptic DLG regulates synaptic function through the localization of voltage-activated Ca2+Channels. Sci Rep 6:1-14.

Balklava Z, Niehage C, Currinn H, Mellor L, Guscott B, Poulin G, Hoflack B, Wassmer T (2015) The amyloid precursor protein controls PIKfyve function. PLoS One 10:1-18.

Baust T, Czupalla C, Krause E, Bourel-Bonnet L, Hoflack B (2006) Proteomic analysis of adaptor protein 1A coats selectively assembled on liposomes. Proc Natl Acad Sci U S A 103:3159-3164.

Beher D, Hesse L, Masters CL, Multhaup G (1996) Regulation of amyloid protein precursor (APP) binding to collagen and mapping of the binding sites on APP and collagen type I. J Biol Chem 271:1613-1620. 
Bourdet I, Preat T, Goguel V (2015) The Full-Length Form of the Drosophila Amyloid Precursor Protein Is Involved in Memory Formation. J Neurosci 35:1043-1051.

Bouzaiane E, Trannoy S, Scheunemann L, Plaçais PY, Preat T (2015) Two Independent Mushroom Body Output Circuits Retrieve the Six Discrete Components of Drosophila Aversive Memory. Cell Rep 11:1280-1292.

Brand AH, Perrimon N (1993) Targeted gene expression as a means of altering cell fates and generating dominant phenotypes. Development 118:401-415.

Butz S, Okamoto M, Sudhof TC (1998). A tripartite protein complex with the potential to couple synaptic vesicle exocytosis to cell adhesion in brain. Cell 94, 773-782

Chen K, Featherstone DE (2011) Pre and postsynaptic roles for Drosophila CASK. Mol Cell Neurosci 48:171-182.

Cho KO, Hunt CA, Kennedy MB (1992) The rat brain postsynaptic density fraction contains a homolog of the drosophila discs-large tumor suppressor protein. Neuron 9:929-942.

Colomb J, Kaiser L, Chabaud MA, Preat T (2009) Parametric and genetic analysis of Drosophila appetitive long-term memory and sugar motivation. Genes, Brain Behav $8: 407-415$.

Conboy L, Murphy KJ, Regan CM (2005) Amyloid precursor protein expression in the rat hippocampal dentate gyrus modulates during memory consolidation. J Neurochem 95:1677-1688. 
Crittenden JR, Skoulakis EMC, Han K-A, Kalderon D, Davis RL (1998) Tripartite Mushroom Body Architecture Revealed by Antigenic Markers. Learn Mem 5:38-51.

Currinn H, Guscott B, Balklava Z, Rothnie A, Wassmer T (2016) APP controls the formation of $\mathrm{PI}(3,5) \mathrm{P}(2)$ vesicles through its binding of the PIKfyve complex. Cell Mol Life Sci 73: 393-408.

Doyle E, Bruce MT, Breen KC, Smith DC, Anderton B, Regan CM (1990) Intraventricular infusions of antibodies to amyloid- $\beta$-protein precursor impair the acquisition of a passive avoidance response in the rat. Neurosci Lett 115:97-102.

Ehrlich I, Malinow R (2004) Postsynaptic Density 95 controls AMPA Receptor Incorporation during Long-Term Potentiation and Experience-Driven Synaptic Plasticity. J Neurosci 24:916-927.

Fulterer A, Andlauer TFM, Ender A, Maglione M, Eyring K, Woitkuhn J, Lehmann M, Matkovic-Rachid T, Geiger JRP, Walter AM, Nagel KI, Sigrist SJ (2018) Active Zone Scaffold Protein Ratios Tune Functional Diversity across Brain Synapses. Cell Rep 23:1259-1274.

Goguel V, Belair A-L, Ayaz D, Lampin-Saint-Amaux A, Scaplehorn N, Hassan BA, Preat T (2011) Drosophila Amyloid Precursor Protein-Like Is Required for Long-Term Memory. J Neurosci 31:1032-1037.

Gross GG, Lone GM, Leung LK, Hartenstein V, Guo M (2013) X11/Mint Genes Control Polarized Localization of Axonal Membrane Proteins in Vivo. J Neurosci 33:85758586. 
Gupta VK, Pech U, Bhukel A, Fulterer A, Ender A, Mauermann SF, Andlauer TF, AntwiAdjei E, Beuschel C, Thriene K, Maglione M, Quentin C, Bushow R, Schwärzel M, Mielke T, Madeo F, Dengjel J, Fiala A, Sigrist SJ, (2016) Spermidine Suppresses Age-Associated Memory Impairment by Preventing Adverse Increase of Presynaptic Active Zone Size and Release. PLoS Biol. 14(9):e1002563

Hata Y, Butz S, Südhof TC (1996) CASK: a novel dlg/PSD95 homolog with an N-terminal calmodulin-dependent protein kinase domain identified by interaction with neurexins. J Neurosci 16:2488-2494.

Haynes PR, Christmann BL, Griffith LC (2015) A single pair of neurons links sleep to memory consolidation in Drosophila melanogaster. Elife 4:e03868.

Heisenberg M (2003) Mushroom body memoir: From maps to models. Nat Rev Neurosci $4: 266-275$.

Hodge JJL, Mullasseril P, Griffith LC (2006) Activity-Dependent Gating of CaMKII Autonomous Activity by Drosophila CASK. Neuron 51:327-337.

Hoe HS, Fu Z, Makarova A, Lee JY, Lu C, Feng L, Pajoohesh-Ganji A, Matsuoka Y, Hyman BT, Ehlers MD, Vicini S, Pak DTS, Rebeck GW (2009) The effects of amyloid precursor protein on postsynaptic composition and activity. J Biol Chem 284:84958506.

Hubner NC, Bird AW, Cox J, Splettstoesser B, Bandilla P, Poser I, Hyman A, Mann M (2010) Quantitative proteomics combined with BAC TransgeneOmics reveals in vivo protein interactions. J Cell Biol 189:739-754. 
Ito K, Awano W, Suzuki K, Hiromi Y, Yamamoto D (1997) The Drosophila mushroom body is a quadruple structure of clonal units each of which contains a virtually identical set of neurones and glial cells. Development 124:761-771.

Jenett A et al. (2012) A GAL4-Driver Line Resource for Drosophila Neurobiology. Cell Rep 2:991-1001.

Kim E, Cho KO, Rothschild A, Sheng M (1996) Heteromultimerization and NMDA receptor-clustering activity of Chapsyn-110, a member of the PSD-95 family of proteins. Neuron 17:103-113.

Kim E, Sheng M (2004) PDZ domain proteins of synapses. Nat Rev Neurosci 5:771-781.

Kittel RJ, Wichmann C, Rasse TM, Fouquet W, Schmidt M, Schmid A, Wagh DA, Pawlu C, Kellner RR, Willig KI, Hell SW, Buchner E, Heckmann M, Sigrist SJ (2006) Bruchpilot Promotes Active Zone Assembly, Ca2+ Channel Clustering, and Vesicle Release. Science 312:1051-1054.

Krashes MJ, Keene AC, Leung B, Armstrong JD, Waddell S (2007) Sequential Use of Mushroom Body Neuron Subsets during Drosophila Odor Memory Processing. Neuron $53: 103-115$.

Krashes MJ, Waddell S (2008) Rapid consolidation to a radish and protein synthesisdependent long-term memory after single-session appetitive olfactory conditioning in Drosophila. J Neurosci 28:3103-3113. 
Lee P-T, Lin H-W, Chang Y-H, Fu T-F, Dubnau J, Hirsh J, Lee T, Chiang A-S (2011) Serotonin-mushroom body circuit modulating the formation of anesthesia-resistant memory in Drosophila. Proc Natl Acad Sci U S A 108:13794-13799.

Leonoudakis D, Conti LR, Radeke CM, McGuire LMM, Vandenberg CA (2004) A Multiprotein Trafficking Complex Composed of SAP97, CASK, Veli, and Mint1 Is Associated with Inward Rectifier Kir2 Potassium Channels. J Biol Chem 279:1905119063.

Lin EI, Jeyifous O, Green WN (2013) CASK Regulates SAP97 Conformation and Its Interactions with AMPA and NMDA Receptors. J Neurosci 33:12067-12076.

Luo LQ, Martin-Morris LE, White K (1990) Identification, secretion, and neural expression of APPL, a Drosophila protein similar to human amyloid protein precursor. J Neurosci $10: 3849-3861$.

Mackler JM, Drummond JA, Loewen CA, Robinson IM, Reist NE (2002) The C2B Ca2+binding motif of synaptotagmin is required for synaptic transmission in vivo. Nature 418:340-344.

Malik BR, Gillespie JM, Hodge JJL (2013) CASK and CaMKII function in the mushroom body $\alpha^{\prime} / \beta^{\prime}$ neurons during Drosophila memory formation. Front Neural Circuits 7:52.

Marcello E, Gardoni F, Mauceri D, Romorini S, Jeromin A, Epis R, Borroni B, Cattabeni F, Sala C, Padovani A, Di Luca M (2007) Synapse-Associated Protein-97 Mediates alphaSecretase ADAM10 Trafficking and Promotes Its Activity. J Neurosci 27:1682-1691. 
McGuire SE, Le PT, Osborn AJ, Matsumoto K, Davis RL (2003) Spatiotemporal Rescue of Memory Dysfunction in Drosophila. Science 302:1765-1768.

Montagna E, Dorostkar MM, Herms J (2017) The Role of APP in Structural Spine Plasticity. Front Mol Neurosci 10:1-7.

Mucke L, Selkoe DJ (2012) Neurotoxicity of amyloid $\beta$-protein: Synaptic and network dysfunction. Cold Spring Harb Perspect Med 2.

Niehage C, Stange C, Anitei M, Hoflack B (2014) Liposome-based assays to study membrane-associated protein networks. Methods Enzymol., 534:223-243.

Okamoto M, Südhof TC (1997) Mints, Munc 18-interacting proteins in synaptic vesicle exocytosis. J Biol Chem 272:31459-31464.

Oliva C, Escobedo P, Astorga C, Molina C, Sierralta J (2012) Role of the MAGUK protein family in synapse formation and function. Dev Neurobiol 72:57-72.

Palop JJ, Mucke L (2010) Amyloid-B-induced neuronal dysfunction in Alzheimer's disease: From synapses toward neural networks. Nat Neurosci 13:812-818.

Pocha SM, Wassmer T, Niehage C, Hoflack B, Knust E (2011) Retromer controls epithelial cell polarity by trafficking the apical determinant crumbs. Curr Biol 21:1111-1117.

Poo M ming, Pignatelli M, Ryan TJ, Tonegawa S, Bonhoeffer T, Martin KC, Rudenko A, Tsai LH, Tsien RW, Fishell G, Mullins C, Gonçalves JT, Shtrahman M, Johnston ST, Gage FH, Dan Y, Long J, Buzsáki G, Stevens C (2016) What is memory? The present state of the engram. BMC Biol 14:1-18. 
Porter AP, White GRM, Mack NA, Malliri A. (2019) The interaction between CASK and the tumour suppressor Dlg1 regulates mitotic spindle orientation in mammalian epithelia. J Cell Sci. 15;132(14).

Preat T, Goguel V (2016) Role of Drosophila Amyloid Precursor Protein in Memory Formation. Front Mol Neurosci 9:1-7.

Rice HC, Young-Pearse TL, Selkoe DJ (2013) Systematic evaluation of candidate ligands regulating ectodomain shedding of Amyloid precursor protein. Biochemistry 52:32643277.

Rieche F, Carmine-Simmen K, Poeck B, Kretzschmar D, Strauss R (2018) Drosophila FullLength Amyloid Precursor Protein Is Required for Visual Working Memory and Prevents Age-Related Memory Impairment. Curr. Biol. 28: 817-823.

Shariati SAM, De Strooper B (2013) Redundancy and divergence in the amyloid precursor protein family. FEBS Lett 587:2036-2045.

Slomnicki LP, Lesniak W (2008) A putative role of the amyloid precursor protein (APP) intracellular domain (AICD) in transcription. Acta Neurobiol Exp (Wars) 68:219-228.

Soukup SF, Pocha SM, Yuan M, Knust E (2013) DLin-7 is required in postsynaptic lamina neurons to prevent light-induced photoreceptor degeneration in Drosophila. Curr Biol 23:1349-1354.

Styr B, Slutsky I (2018) Imbalance between firing homeostasis and synaptic plasticity drives early-phase Alzheimer's disease. Nat Neurosci 21:463-473. 
Südhof TC (2004) The synaptic vesicle cycle. Annu Rev Neurosci 27:509-547.

Tejedor FJ, Bokhari A, Rogero O, Gorczyca M, Zhang J, Kim E, Sheng M, Budnik V (1997) Essential role for $\mathrm{dlg}$ in synaptic clustering of Shaker $\mathrm{K}+$ channels in vivo. $\mathrm{J}$ Neurosci $17: 152-159$.

Tempel BL, Bonini N, Dawson DR, Quinn WG (1983) Reward learning in normal and mutant Drosophila. Proc Natl Acad Sci 80:1482-1486.

Thomas U, Kobler O, Gundelfinger ED (2010) The Drosophila larval neuromuscular junction as a model for scaffold complexes at glutamatergic synapses: Benefits and limitations. J Neurogenet 24:109-119.

Torroja L, Luo L, White K (1996) APPL, the Drosophila member of the APP-family, exhibits differential trafficking and processing in CNS neurons. J Neurosci 16:4638-4650.

Torroja L, Packard M, Gorczyca M, White K, Budnik V. (1999) The Drosophila betaamyloid precursor protein homolog promotes synapse differentiation at the neuromuscular junction. J Neurosci. 19:7793-803.

Trannoy S, Redt-Clouet C, Dura JM, Preat T (2011) Parallel processing of appetitive shortand long-term memories in Drosophila. Curr Biol 21:1647-1653.

Turrel O, Lampin-Saint-Amaux A, Preat T, Goguel V (2016) Drosophila Neprilysins Are Involved in Middle-Term and Long-Term Memory. 36:9535-9546.

Turrel O, Goguel V, Preat T (2017) Drosophila Neprilysin 1 Rescues Memory Deficits Caused by Amyloid- $\beta$ Peptide. J Neurosci 37:10334-10345. 
Walter AM, Böhme MA, Sigrist SJ (2018) Vesicle release site organization at synaptic active zones. Neurosci Res 127:3-13.

Wang Z, Wang B, Yang L, Guo Q, Aithmitti N, Songyang Z, Zheng H (2009) Presynaptic and Postsynaptic Interaction of the Amyloid Precursor Protein Promotes Peripheral and Central Synaptogenesis. J Neurosci 29:10788-10801.

Williamson TG, Mok SS, Henry A, Cappai R, Lander AD, Nurcombe V, Beyreuther K, Masters CL, Small DH (1996) Secreted glypican binds to the amyloid precursor protein of Alzheimer's disease (APP) and inhibits APP-induced neurite outgrowth. J Biol Chem 271:31215-31221.

Woods DF, Bryant PJ (1991) The discs-large tumor suppressor gene of Drosophila encodes a guanylate kinase homolog localized at septate junctions. Cell 66:451-464.

Yang CH, Shih MFM, Chang CC, Chiang MH, Shih HW, Tsai YL, Chiang AS, Fu TF, Wu CL (2016) Additive Expression of Consolidated Memory through Drosophila Mushroom Body Subsets. PLoS Genet 12:1-21.

Yang MY, Armstrong JD, Vilinsky I, Strausfeld NJ, Kaiser K (1995) Subdivision of the Drosophila mushroom bodies by enhancer-trap expression patterns. Neuron 15:45-54.

Zheng H, Koo EH (2011) Biology and pathophysiology of the amyloid precursor protein. Mol Neurodegener 6:1-16. 


\section{FigURES}

(A)

LTM

2d Induced

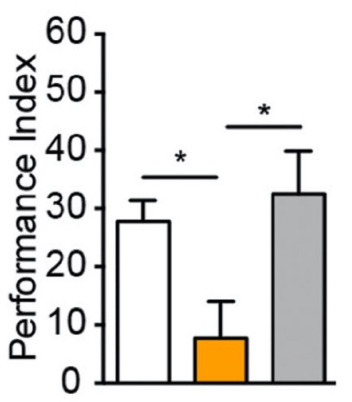

tub-Gal80ts;238Y/+ tub-Gal80ts;238Y> APPLRNAi1 APPL $^{\text {RNAi1 } /+}$

(D)

$$
\begin{gathered}
\text { LTM } \\
\text { 2d Induced }
\end{gathered}
$$

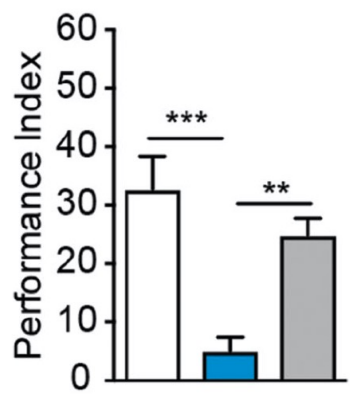

$\square$ tub-Gal80ts $; 238 \mathrm{Y} /+$

tub-Gal80ts;238Y>

APPL RNAi2

$\mathrm{APPL}^{\mathrm{RNAi} 2 /+}$
(B)

LTM

Non-induced

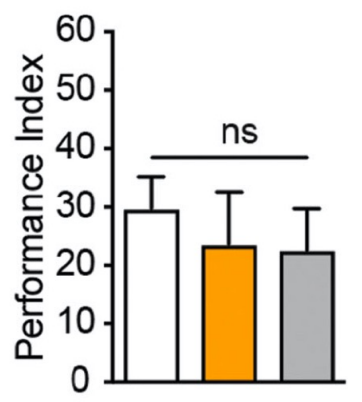

(C)

STM 2d Induced

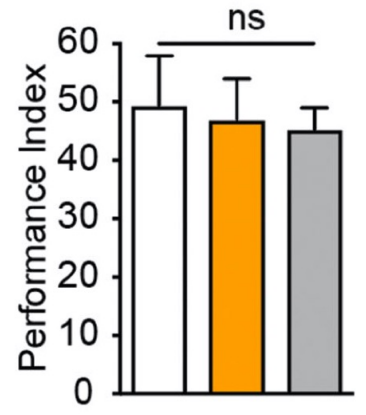

(E)

LTM
Non-induced

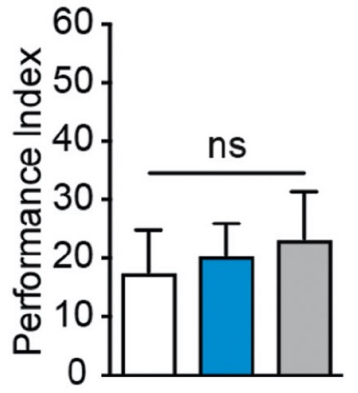

(F)

STM 2d Induced

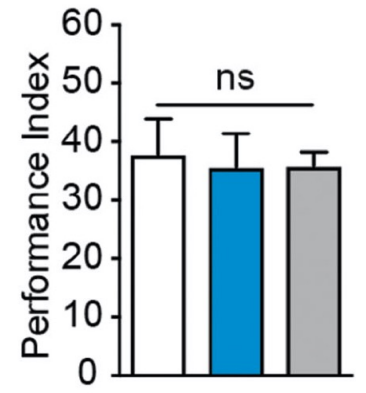

Figure 1. APPL is required in the adult MB for appetitive LTM

$\boldsymbol{A}-\boldsymbol{B}$, APPL downregulation in the adult MB impaired $\operatorname{LTM}\left(\boldsymbol{A}, \mathrm{n}=7-8, \mathrm{~F}_{2,20}=5.23, \mathrm{p}=0.0149\right)$, whereas the non-induced controls displayed normal LTM $\left(\boldsymbol{B}, \mathrm{n}=10-9, \mathrm{~F}_{2,27}=0.27, \mathrm{p}=0.76\right)$. $\boldsymbol{C}, A P P L^{R N A i l}$ expression in the adult MB did not affect $\mathrm{STM}\left(\mathrm{n}=11, \mathrm{~F}_{2,30}=0.28, \mathrm{p}=0.76\right)$. $\boldsymbol{D}$ $\boldsymbol{F}$, Similar results were observed using a second non-overlapping APPL RNAi. Flies expressing $A P P L^{R N A i 2}$ in the adult MB displayed a LTM defect $\left(\boldsymbol{D}, \mathrm{n}=7, \mathrm{~F}_{2,18}=13.03\right.$, 
$\mathrm{p}=0.0003)$, whereas the non-induced controls showed normal $\operatorname{LTM}\left(\boldsymbol{E}, \mathrm{n}=11, \mathrm{~F}_{2,30}=0.16\right.$, $\mathrm{p}=0.85) . \boldsymbol{F}$, APPL downregulation using $A P P L^{R N A i 2}$ did not affect $\operatorname{STM}\left(\mathrm{n}=11-9, \mathrm{~F}_{2,26}=0.012\right.$, $\mathrm{p}=0.95)$. Data are shown as mean \pm SEM. Statistical analyses were performed using one-way ANOVA followed by a post hoc Newman-Keuls test $(* * \mathrm{p}<0.01$, ns: not significant). $2 \mathrm{~d}$, two days.

\section{Intracellular interactome of APP}

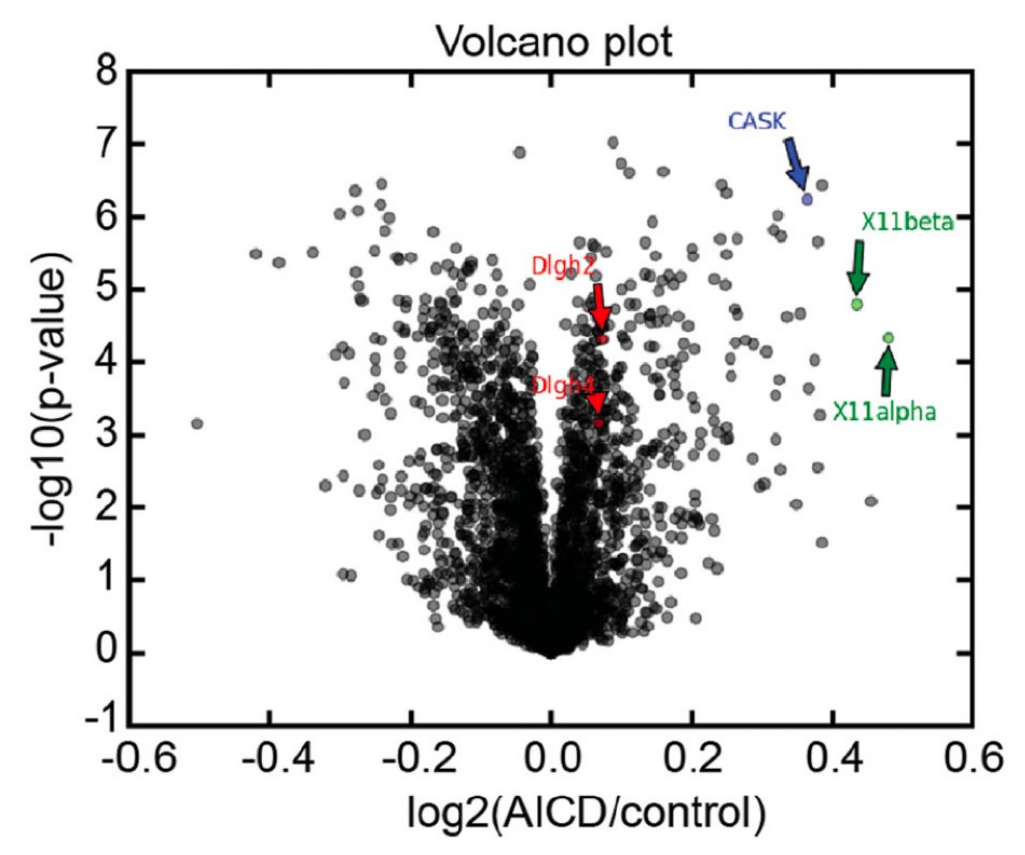

Figure 2. The intracellular domain of mammalian APP binds X11 $\alpha$, X11 $\beta$, CASK and DLG homologs 2 and 4

Proteo-liposomes functionalized with AICD were used as bait to isolate the intracellular interaction partners of APP, and were then compared to control proteo-liposomes. The plot shows the relative enrichment of the identified protein in the AICD sample versus the control (plotted as $\log _{2}$ on the $\mathrm{x}$-axis) and the $\mathrm{p}$-value of Student's t-test (plotted as $\log _{10}$ on the $\mathrm{y}$ axis). Each data point represents the average measurement of three independent experiments. The significantly enriched AICD interaction partners CASK, X11 $\alpha, \mathrm{X} 11 \beta, \mathrm{Dlgh} 2$ and Dlgh4 
are indicated.

(A)

LTM

2d Induced

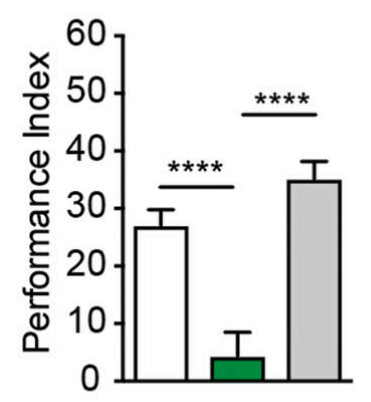

$\square$ tub-Gal80ts;238Y/+

tub-Gal80ts;238Y> CASK ${ }^{\text {RNAi1 }}$

$\square$ CASK $^{\mathrm{RNAi} 1 /+}$

(C)

LTM

2d Induced

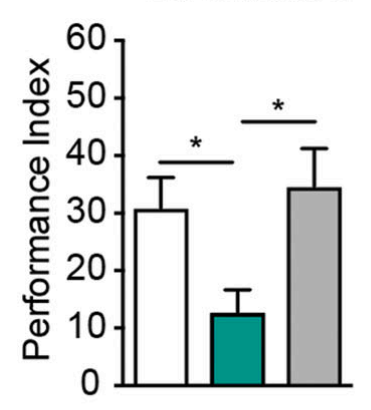

$\square$ tub-Gal80ts; $238 \mathrm{Y} /+$

tub-Gal80ts $; 238 Y>$

CASKRNAi2

$\mathrm{CASK}^{\mathrm{RNAi} /+}$
(B) $\quad$ LTM

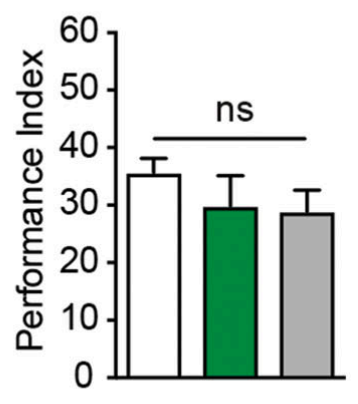

(D) LTM

Non-induced

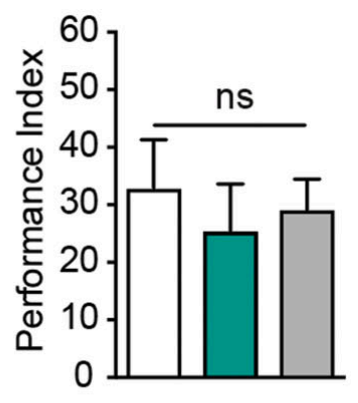

Figure 3. CASK is required in the adult MB for appetitive memory

$\boldsymbol{A}-\boldsymbol{B}, \mathrm{CASK}$ downregulation in the adult MB impaired $\operatorname{LTM}\left(\boldsymbol{A}, \mathrm{n}=11-12, \mathrm{~F}_{2,31}=22.84\right.$, $\mathrm{p}<0.0001)$, whereas the non-induced controls displayed normal $\operatorname{LTM}\left(\boldsymbol{B}, \mathrm{n}=12, \mathrm{~F}_{2,33}=0.83\right.$, $\mathrm{p}=0.44) . \boldsymbol{C}-\boldsymbol{D}, \mathrm{CASK}$ downregulation in the adult MB using a second non-overlapping RNAi $\left(C A S K^{R N A i 2}\right)$ impaired $\operatorname{LTM}\left(\boldsymbol{C}, \mathrm{n}=12, \mathrm{~F}_{2,33}=4.72, \mathrm{p}=0.016\right)$, whereas LTM was normal in the absence of induction $\left(\boldsymbol{D}, \mathrm{n}=8, \mathrm{~F}_{2,21}=0.25, \mathrm{p}=0.77\right)$. Data are shown as mean $\pm \mathrm{SEM}$. Statistical 
analyses were performed using one-way ANOVA followed by a post hoc Newman-Keuls test $(* \mathrm{p}<0.05, * * \mathrm{p}<0.01, * * * \mathrm{p}<0.001$, ns: not significant).

(A)

LTM

2d Induced

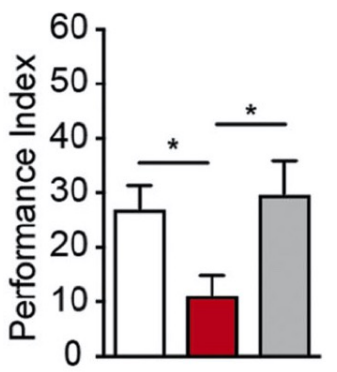

tub-Gal80ts;238Y/+

tub-Gal80 $80^{\text {ts }} 238 \mathrm{Y}>$

D $\operatorname{gg}^{\text {RNAi1 }}$

D $\lg ^{\mathrm{RNAi1} /+}$

(C)

LTM

2d Induced

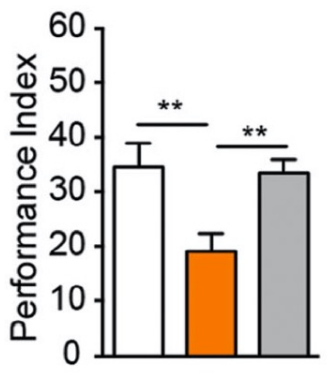

tub-Gal80ts;238Y/+

tub-Gal80 ${ }^{\text {ts }} ; 238 Y>$

DIgRNAi2

DIgRNAi2/+
(B) LTM

Non-induced

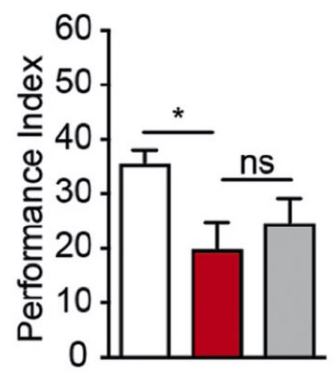

(D) LTM

Non-induced

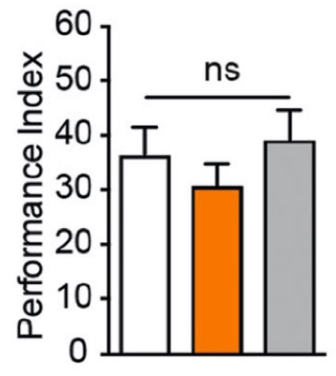

Figure 4. DLG is required in the adult MB for appetitive memory

$\boldsymbol{A}-\boldsymbol{B}, \mathrm{Dlg}$ downregulation in the adult MB impaired LTM $\left(\boldsymbol{A}, \mathrm{n}=10, \mathrm{~F}_{2,27}=4.42, \mathrm{p}=0.022\right)$, whereas the non-induced controls displayed normal $\operatorname{LTM}\left(\boldsymbol{B}, \mathrm{n}=12, \mathrm{~F}_{2,33}=3.93, \mathrm{p}=0.030\right)$. The post hoc Newman-Keuls test comparison was not significant for $D \lg ^{R N A i l} /+$ versus either tub-Gal80 ${ }^{t s} ; 238 Y>D l g^{R N A i l}$ or tub-Gal80 ${ }^{t s} ; 238 Y /+$, although it was significant for tub-

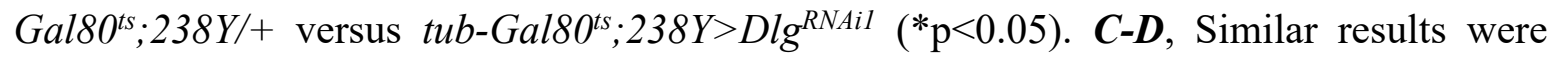


observed using a second non-overlapping Dlg RNAi, $D \lg ^{R N A i 2}$.Flies expressing $D \lg ^{R N A i 2}$ in the adult MB displayed a LTM defect $\left(\boldsymbol{C}, \mathrm{n}=16-17, \mathrm{~F}_{2,46}=6.16, \mathrm{p}=0.004\right)$, whereas the noninduced controls showed normal $\operatorname{LTM}\left(\boldsymbol{D}, \mathrm{n}=12, \mathrm{~F}_{2,33}=0.79, \mathrm{p}=0.46\right)$. Data are shown as mean \pm SEM. Statistical analyses were performed using one-way ANOVA followed by a post hoc Newman-Keuls test $\left(* \mathrm{p}<0.05,{ }^{*} \mathrm{p}<0.01\right.$, ns: not significant).
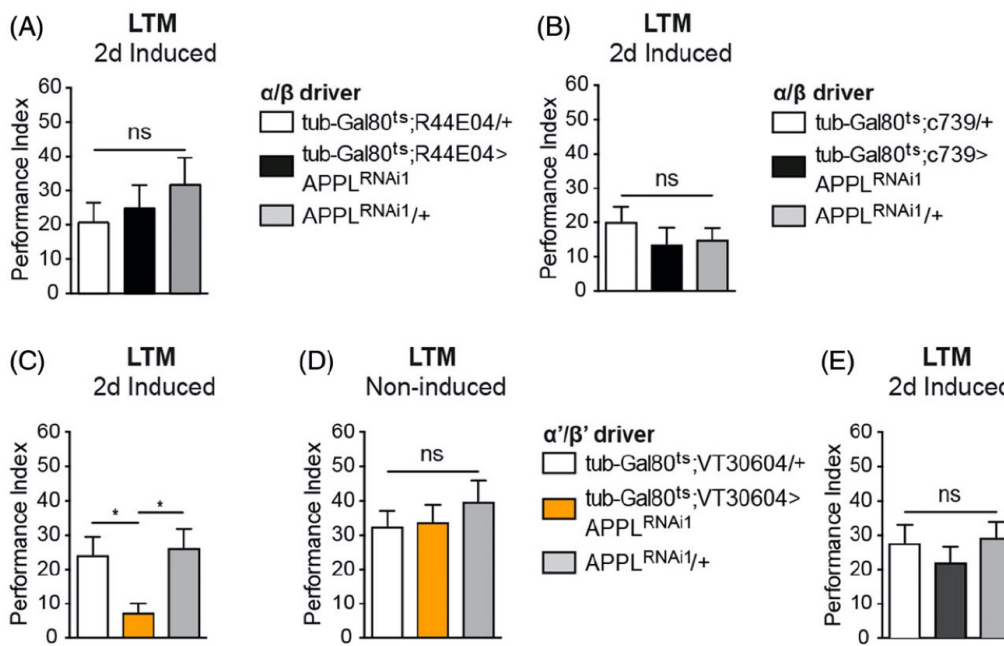

(D) $\quad \underset{\text { LTM }}{\text { Non-induced }}$
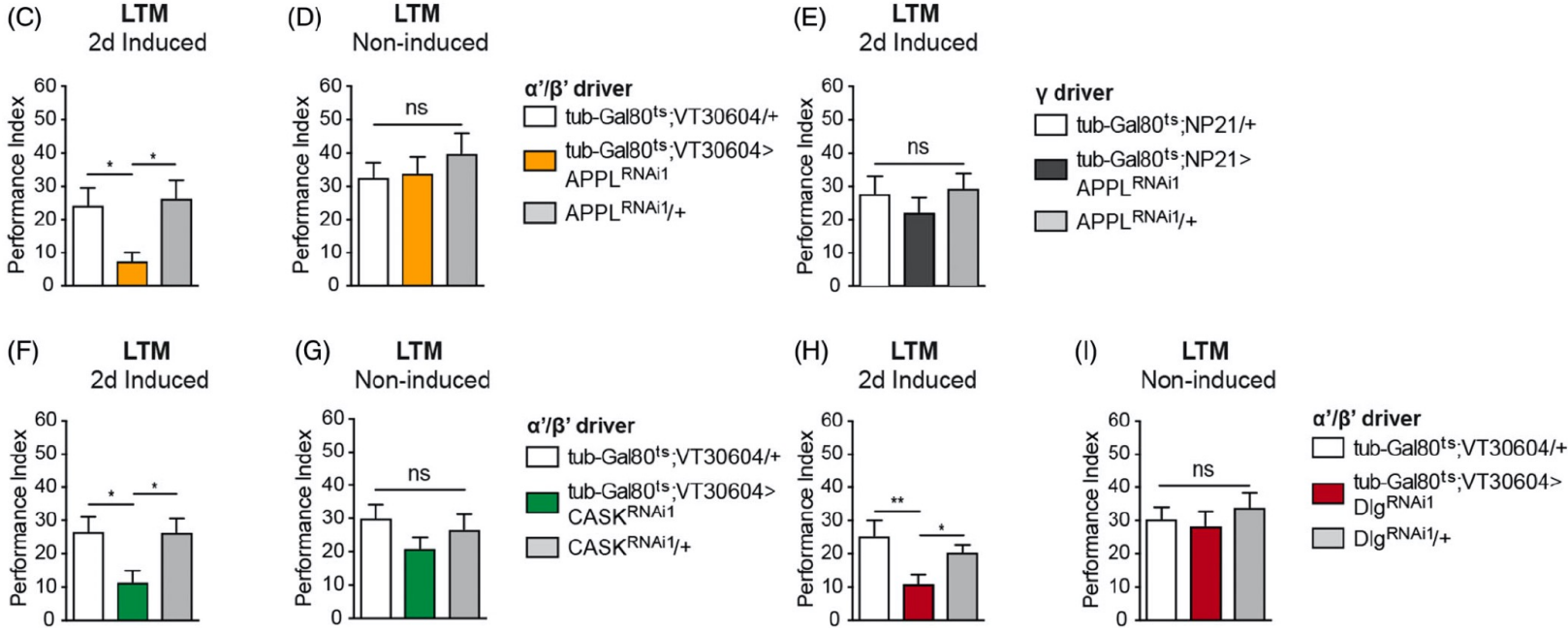

Figure 5. APPL, CASK and DIg are required specifically in the $\alpha^{\prime} / \beta$ ' neurons for appetitive LTM

$\boldsymbol{A}$, APPL downregulation in the adult $\alpha / \beta$ neurons using the $t u b-G a l 80^{\text {ts }} ; R 44 E 04$ driver did not impair LTM $\left(\mathrm{n}=7, \mathrm{~F}_{2,18}=0.78, \mathrm{p}=0.47\right) . \boldsymbol{B}$, Similar results were obtained using the $t u b$ Gal80 $^{t s} ; c 739$ driver to control the expression of $A P P L^{R N A i l}$ in the adult $\alpha / \beta$ neurons $(n=10-$ $\left.12, \mathrm{~F}_{2,28}=0.64, \mathrm{p}=0.54\right) . \boldsymbol{C}-\boldsymbol{D}$, APPL downregulation in the adult $\alpha^{\prime} / \beta^{\prime}$ neurons using the $t u b$ Gal80 $^{\text {ts }}$;VT30604 driver impaired LTM $\left(\mathbf{C}, \mathrm{n}=12, \mathrm{~F}_{2,33}=5.025, \mathrm{p}=0.0124\right)$, whereas the non- 
induced controls displayed normal $\operatorname{LTM}\left(\boldsymbol{D}, \mathrm{n}=13, \mathrm{~F}_{2,36}=0.56, \mathrm{p}=0.58\right) . \quad \boldsymbol{E}$, APPL downregulation in the adult $\gamma$ neurons using the $t u b-G a l 80^{t s} ; N P 21$ driver did not impair LTM $\left(\mathrm{n}=16, \mathrm{~F}_{2,45}=0.69, \mathrm{p}=0.51\right) . \boldsymbol{F}-\boldsymbol{G}, \mathrm{CASK}$ downregulation in the adult $\alpha^{\prime} / \beta^{\prime}$ neurons impaired $\operatorname{LTM}\left(\boldsymbol{F}, \mathrm{n}=12, \mathrm{~F}_{2,33}=4.905, \mathrm{p}=0.0137\right)$, whereas the non-induced controls displayed normal $\operatorname{LTM}\left(\boldsymbol{G}, \mathrm{n}=12, \mathrm{~F}_{2,33}=1.30, \mathrm{p}=0.29\right) . \boldsymbol{H}-\boldsymbol{I}, \mathrm{Dlg}$ downregulation in the adult $\alpha^{\prime} / \beta^{\prime}$ neurons impaired LTM $\left(\boldsymbol{H}, \mathrm{n}=17, \mathrm{~F}_{2,48}=5.04, p=0.010\right)$, whereas the non-induced controls displayed normal $\operatorname{LTM}\left(\boldsymbol{I}, \mathrm{n}=12, \mathrm{~F}_{2,33}=0.49, \mathrm{p}=0.61\right)$. Data are shown as mean $\pm \mathrm{SEM}$. Statistical analyses were performed using one-way ANOVA followed by a post hoc Newman-Keuls test $\left({ }^{*} \mathrm{p}<0.05\right.$, ns: not significant).

(A) $\quad$ LTM
1d Induced

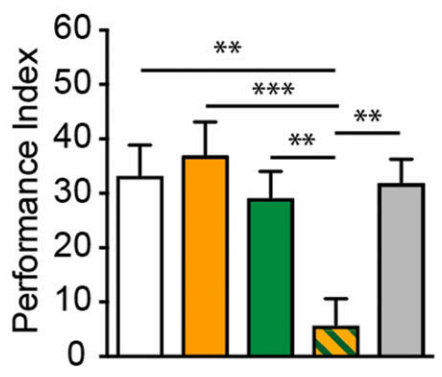

(C)

LTM 1d Induced

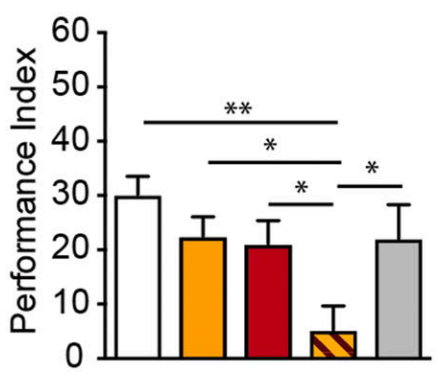

(B) LTM Non-induced

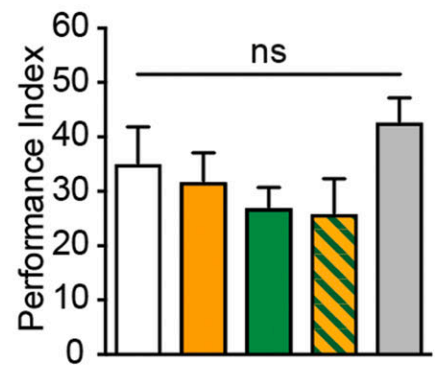

(D)

LTM Non-induced

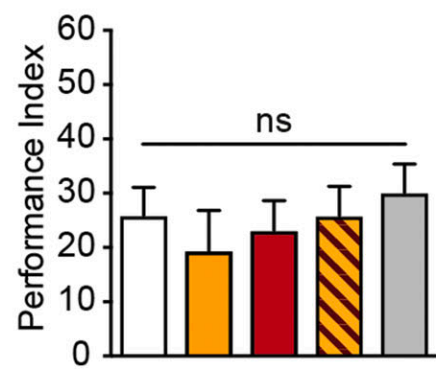

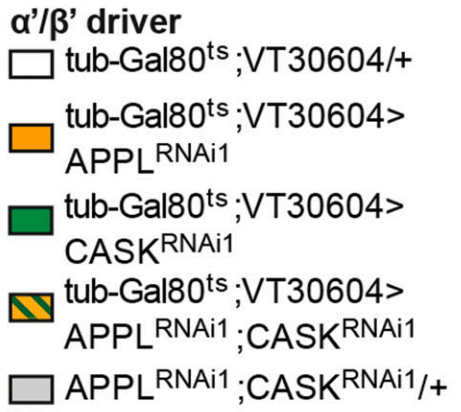

$\alpha^{\prime} / \beta^{\prime}$ driver $\square$ tub-Gal80ts ;VT30604/+ $\square^{\text {tub-Gal80ts }} ;$ VT30604> APPLRNAi1

$\square^{\text {tub-Gal80ts }} ;$ VT30604> DIgRNAi1 tub-Gal80ts ;VT30604> APPL RNAi1; DlgRNAi1 APPLRNAi1;DlgRNAi1/+

Figure 6. Interaction between APPL and MAGUKs is required for appetitive LTM $\boldsymbol{A}-\boldsymbol{B}$, One day of induction to express the double $A P P L^{R N A i l} ; C A S K^{R N A i l}$ construct in the adult $\alpha^{\prime} / \beta^{\prime}$ neurons was sufficient to impair LTM as compared to single RNAi expression $(\boldsymbol{A}, n=12$, 
$\left.\mathrm{F}_{4,55}=5.847, p=0.0005\right)$, whereas the non-induced controls displayed normal $\operatorname{LTM}(\boldsymbol{B}, n=11$, $\left.\mathrm{F}_{4,50}=1.60, p=0.19\right) . \boldsymbol{C}-\boldsymbol{D}$, One day of induction to express the double $A P P L^{R N A i 1} ; D \lg ^{R N A i l}$ construct in the adult $\alpha^{\prime} / \beta^{\prime}$ neurons was sufficient to impair LTM as compared to single RNAi expression $\left(\boldsymbol{C}, \mathrm{n}=12-11, \mathrm{~F}_{4,53}=3.90, \mathrm{p}=0.0075\right)$, whereas the non-induced controls displayed normal $\operatorname{LTM}\left(\boldsymbol{D}, \mathrm{n}=12-11, \mathrm{~F}_{4,54}=0.44, \mathrm{p}=0.78\right)$. Data are shown as mean $\pm \mathrm{SEM}$. Statistical analyses were performed with one-way ANOVA followed by a post hoc Newman-Keuls test $\left({ }^{*} \mathrm{p}<0.05,{ }^{* *} \mathrm{p}<0.01, \mathrm{~ns}\right.$ : not significant). $1 \mathrm{~d}$, one day. 
(A)

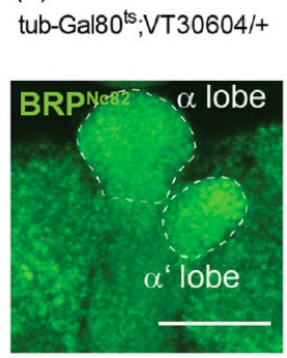

tub-Gal80 ${ }^{\text {ts }}$;VT30604> APPL $^{\text {RNAi1 }} ; \mathrm{CASK}^{\mathrm{RNAi} 1}$

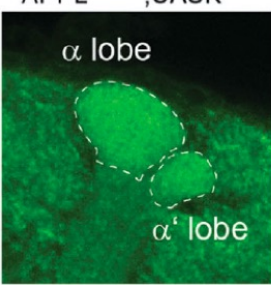

tub-Gal80"s.,$V T 30604>$ APPL $^{\text {RNAi1 }} ; \mathrm{Dlg}^{\text {RNAi1 }}$

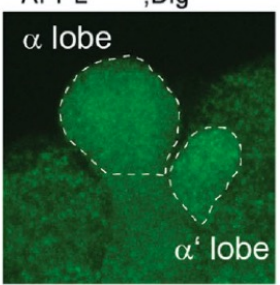

(B)

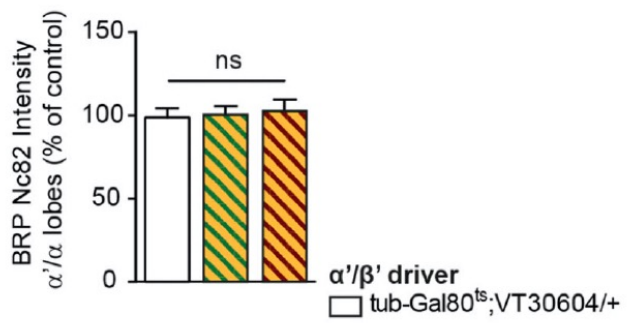

tub-Gal80 ${ }^{\text {ts. }}$,VT30604>

(C)

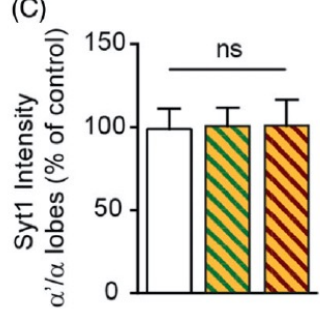
APPL RNAi1;CASK ${ }^{\text {RNAi1 }}$ tub-Gal80 ${ }^{\text {ts. }}$,VT30604>
APPL ${ }^{\text {RNAi1 }} ;$ DIg $^{\text {RNAi1 }}$
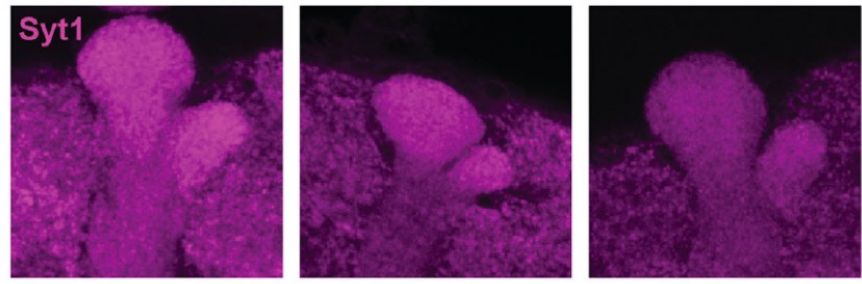

(D) tub-Gal80 $0^{\text {ts }} ; \mathrm{VT} 30604 /+$

tub-Gal80 ts. VT30604> APPL ${ }^{\text {RNAi1 }}:$ CASK $^{\text {RNAi1 }}$

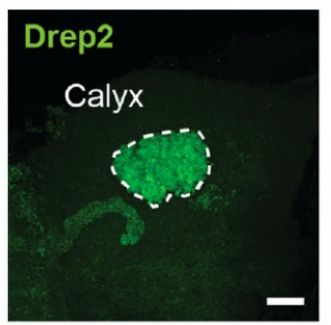

\section{DIg}
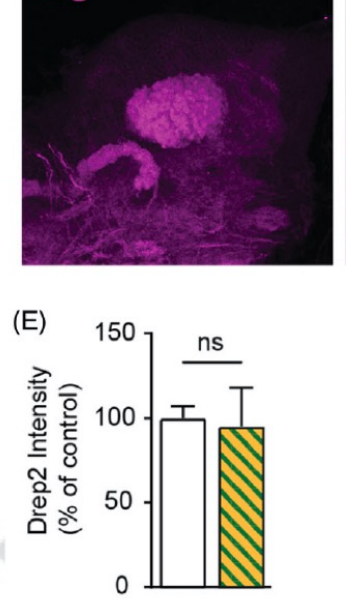

$\alpha^{\prime} / \beta^{\prime}$ driver

$\square$ tub-Gal80 $0^{\text {ts }}$;VT30604/+

$\nabla^{\text {tub-Gal80 }}$;s:VT30604>

APPL ${ }^{\text {RNAi1 }} ;$ CASK $^{\text {RNAi1 }}$

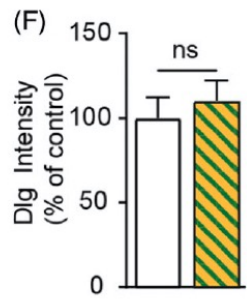

(G) tub-Gal80 $0^{\text {ts }} ; \mathrm{VT} 30604 /+$
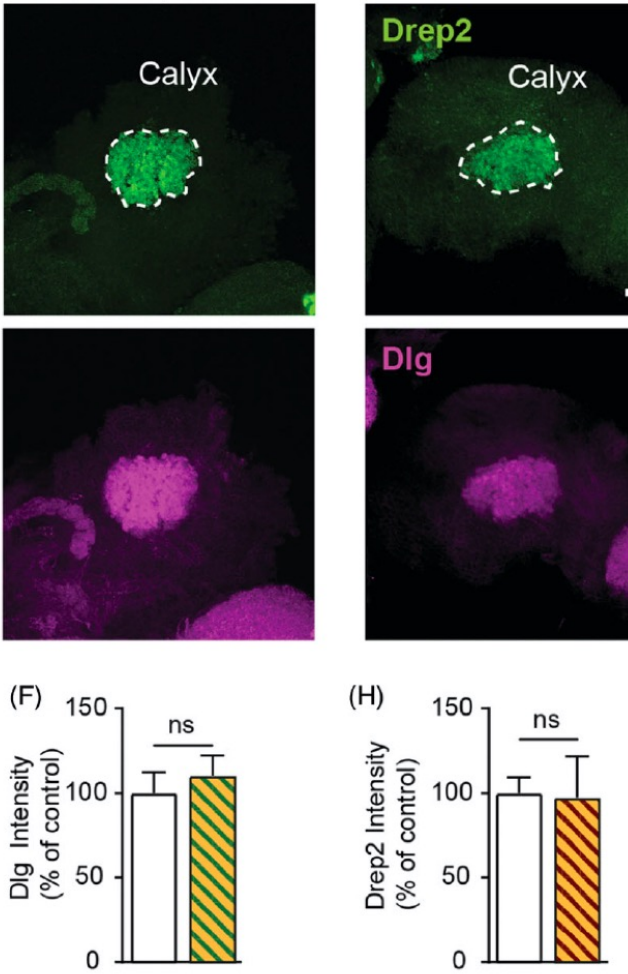

$\alpha^{\prime} / \beta^{\prime}$ driver

$\square$ tub-Gal80 $0^{\text {ts }} ;$ VT30604/+

$\nabla_{\text {tub-Gal80 }}^{\text {ts }} ;$ VT30604>

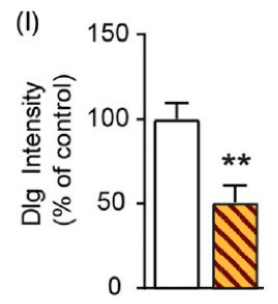

tub-Gal80 ${ }^{\text {ts. }}$ VT30604>

APPL ${ }^{\text {RNAi1 }} ; \mathrm{DIg}^{\text {RNAi1 }}$
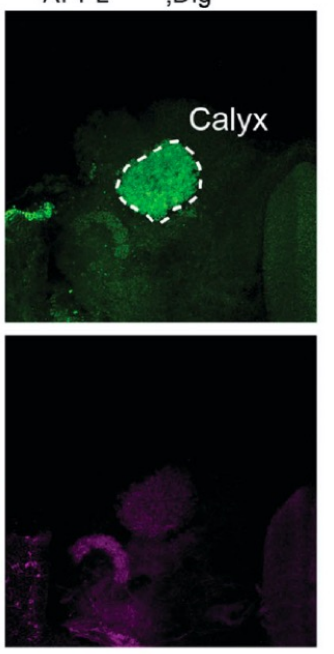

Figure 7. Synaptic organization of MB synapses in APPL; CASK and APPL; Dlg

\section{knock-down flies}


$\boldsymbol{A}$, Max intensity projection of confocal images for Bruchpilot (BRP ${ }^{\mathrm{Nc} 82}$, green, upper panel) and Synaptotagmin 1 (Syt1, magenta, lower panel) showing the tips of the MB $\alpha^{\prime}$ and $\alpha$ lobes

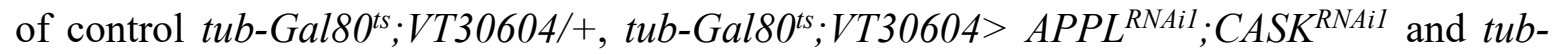
Gal80 ${ }^{t s} ; V T 30604>A P P L^{R N A i l} ; D \lg ^{R N A i l}$ male flies (4-5 days old, 2 days induction). B-C, Graphs show the intensity for $\operatorname{BRP}^{\mathrm{Nc} 82}(\boldsymbol{B})$ and Syt1 $(\boldsymbol{C})$ in $\alpha^{\prime}$ lobes normalized to the $\alpha$ lobes as control region. Expression of either the double $A P P L^{R N A i l} ; C A S K^{R N A i l}$ construct or the double $A P P L^{R N A i l} ; D \lg ^{R N A i l}$ construct in the $\alpha^{\prime} / \beta^{\prime}$ neurons during 2-days did not affect the $\mathrm{BRP}^{\mathrm{Nc} 82}$ or the Syt1 labeling intensity in the $\alpha^{\prime}$ lobe compare to the $t u b-G a l 80^{t s} ;$ VT30604/+ control. (B, BRP ${ }^{\mathrm{Nc} 82}$ intensity: tub-Gal80 $0^{\text {ts }} ;$ VT30604/+: $100 \pm 4, \quad \mathrm{n}=5 ; \quad$ tub-

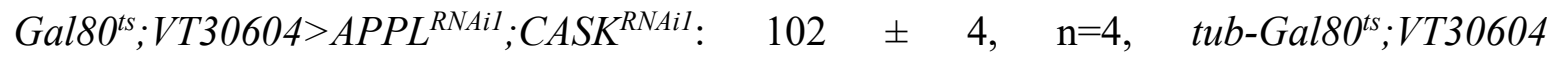
$>A P P L^{R N A i 1} ; \operatorname{Dlg}^{R N A i 1}: 104 \pm 6, \mathrm{n}=4, \mathrm{p}=0.836$; Kruskal-Wallis test. $C$, Syt1 intensity: tub-

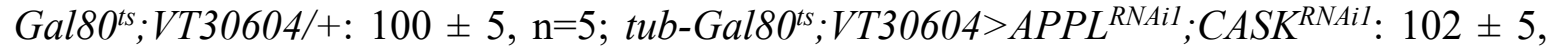

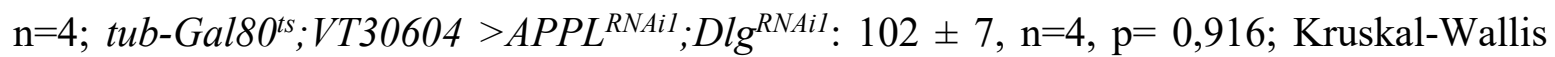
test). This experiment was performed once on different biological replicates. Scale bar: $10 \mu \mathrm{m} . \boldsymbol{D}-\boldsymbol{I}$, Single confocal optical slices of the postsynaptic marker Drep2 (green, upper panel) and Dlg (magenta, lower panel) in the MB calyx of control tub-Gal80 ${ }^{\text {ts }}$;VT30604/+

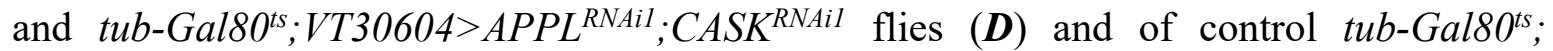
$V T 30604 /+$ and $t u b-G a l 80^{t s} ; V T 30604>A P P L^{R N A i l} ; D l g^{R N A i l}$ flies (G). The corresponding intensity graphs are shown in figures $\boldsymbol{E}-\boldsymbol{F}$, and $\boldsymbol{H}-\boldsymbol{I}$ respectively. $\boldsymbol{E}-\boldsymbol{F}$, Expression of the double $A P P L^{R N A i 1} ; C A S K^{R N A i 1}$ construct in the $\alpha^{\prime} / \beta^{\prime}$ neurons during 2-days did not affect either Dlg or Drep2 intensity through the calyx as compared to control flies (E, Dlg intensity:

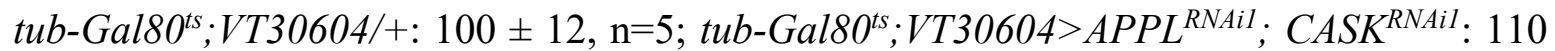
$\pm 12, \mathrm{n}=3, \mathrm{p}=0,571$; Mann Whitney U-test; $\boldsymbol{F}$, Drep2: tub-Gal80 ${ }^{\text {ts }} ; V T 30604 /+: 100 \pm 7 \mathrm{n}=5$; tub-Gal80 ${ }^{\text {ts }}$;VT30604>APPL ${ }^{R N A i l} ; C A S K^{R N A i l}: 95 \pm 23, \mathrm{n}=3, \mathrm{p}=0,571$; Mann Whitney U- 
test). This experiment was performed once on different biological replicates. $\boldsymbol{H}-\boldsymbol{I}$, Expression of the double $A P P L^{R N A i l} ; D \lg ^{R N A i l}$ construct in the $\alpha^{\prime} / \beta^{\prime}$ neurons during 2-days significantly decreases Dlg intensity through the calyx as compared to control flies $(\boldsymbol{H}$, tub-

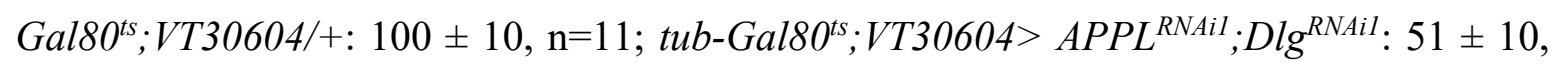
$\mathrm{n}=12, \mathrm{p}=0,0036$; Mann Whitney U-test) without significantly altering Drep2 intensity (I,

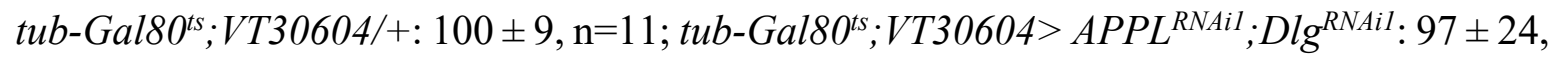
$\mathrm{n}=12, \mathrm{p}=0,260$; Mann Whitney U-test). The experiment was repeated three times on different biological replicates. Values were normalized to controls and indicate mean \pm SEM. $n$ indicates the number of brains analyzed. Scale bar: $20 \mu \mathrm{m}$.

Supplementary Table 1. Intracellular interactome of APP (related to Figure 2). Table showing the results of the proteo-liposome recruitment analyzed by mass-spectrometry. Shown are averages of three independent experiments. Each protein identified in the analysis is shown as a single plot in Figure 2 with the degree of enrichment in the AICD relative to the control sample $(\log 2(\mathrm{AICD} / \mathrm{control})$, Column $\mathrm{A})$ plotted on the $\mathrm{x}$-axis and the negative logarithm of the p-value (-LOG10(p-value), Column B) plotted on the y-axis. In the table only significant hits $(\mathrm{p}<0.05$ student's t-test) are shown.

Supplementary Table 2. Data Table. The data of each experiment are presented in this table. For each figure the data are reported in one excel sheet, except for Figure 2 since the data related to this figure are presented in Supplementary Table 1. 

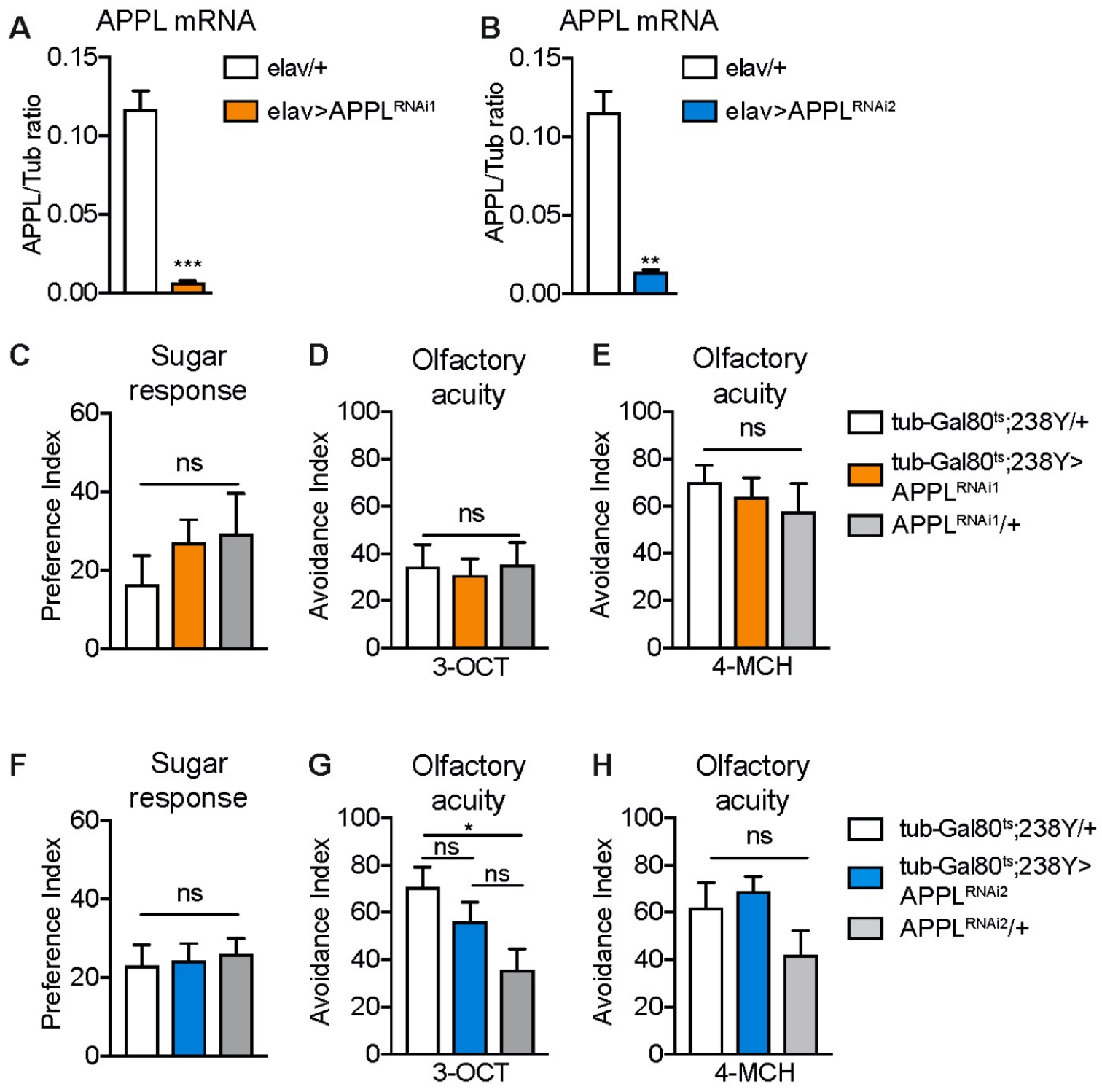

Supplementary Figure 1. APPL RNAi efficiency and sugar response and olfaction acuity in APPL knock-down condition (related to Figure 1).

$\boldsymbol{A}-\boldsymbol{B}$, Total RNA was extracted from elav/+ and elav $>R N A i$ fly heads and subsequently reverse-transcribed using oligo(dT) primers. The resulting cDNA was quantified using tubulin expression as a reference. $\boldsymbol{A}$, Expression of $A P P L^{R N A i l}$ in neurons using the panneuronal driver elav resulted in a significant reduction in APPL mRNA levels $\left(\mathrm{n}=3, \mathrm{t}_{4}=0.007\right.$, $\mathrm{p}=0.0007) . \boldsymbol{B}$, Similarly, expression of $A P P L^{R N A i 2}$ using the pan-neuronal elav driver reduced 
significantly the APPL mRNA levels in fly heads $\left(n=3, t_{4}=7.65, p=0.0016\right)$. The $q P C R$ results are shown as ratios to the reference. Statistical analyses were performed with a two-tailed unpaired $t$-test $(* * * \mathrm{p}<0.001, * * \mathrm{p}<0.01) . C$, The sugar response of flies expressing $A P P L^{R N A i l}$ in the adult MB under the control of $t u b-G a l 80^{t s} ; 238 Y$ driver did not differ from controls $(\mathrm{n}=10-11, \mathrm{~F}(2,29)=0.76, \mathrm{p}=0.47) . \boldsymbol{D}-\boldsymbol{E}$, Normal olfactory acuity was observed in these flies expressing $A P P L^{R N A i 1}$ in the adult $\mathrm{MB}$ exposed to either 3-octanol $(\boldsymbol{D}, \mathrm{n}=8, \mathrm{~F}(2,21)=0.07$, $\mathrm{p}=0.93)$ or 4-methylcyclohexanol $(\boldsymbol{E}, \mathrm{n}=9, \mathrm{~F}(2,24)=0.45, \mathrm{p}=0.63) . \boldsymbol{F}$, The sugar response of flies expressing $A P P L^{R N A i 2}$ in the adult MB under the control of tub-Gal80 $0^{t s} ; 238 Y$ driver did not differ from controls $(\boldsymbol{F}, \mathrm{n}=10, \mathrm{~F}=(2,27)=0.10, \mathrm{p}=0.89) . \boldsymbol{G}-\boldsymbol{H}$ Normal olfactory acuity was observed in these flies expressing $A P P L^{R N A i 2}$ in the adult MB exposed to either 3-octanol ( $\boldsymbol{G}$, $\mathrm{n}=12, \mathrm{~F}(2,33)=4.51, \mathrm{p}=0.018)$ or 4 -methylcyclohexanol $(\boldsymbol{H}, \mathrm{n}=12, \mathrm{~F}(2,33)=2.36, \mathrm{p}=0.10)$. Data are shown as mean \pm SEM. Statistical analyses were performed with one-way ANOVA followed by a post-hoc Newman-Keuls test (ns : not significant). 

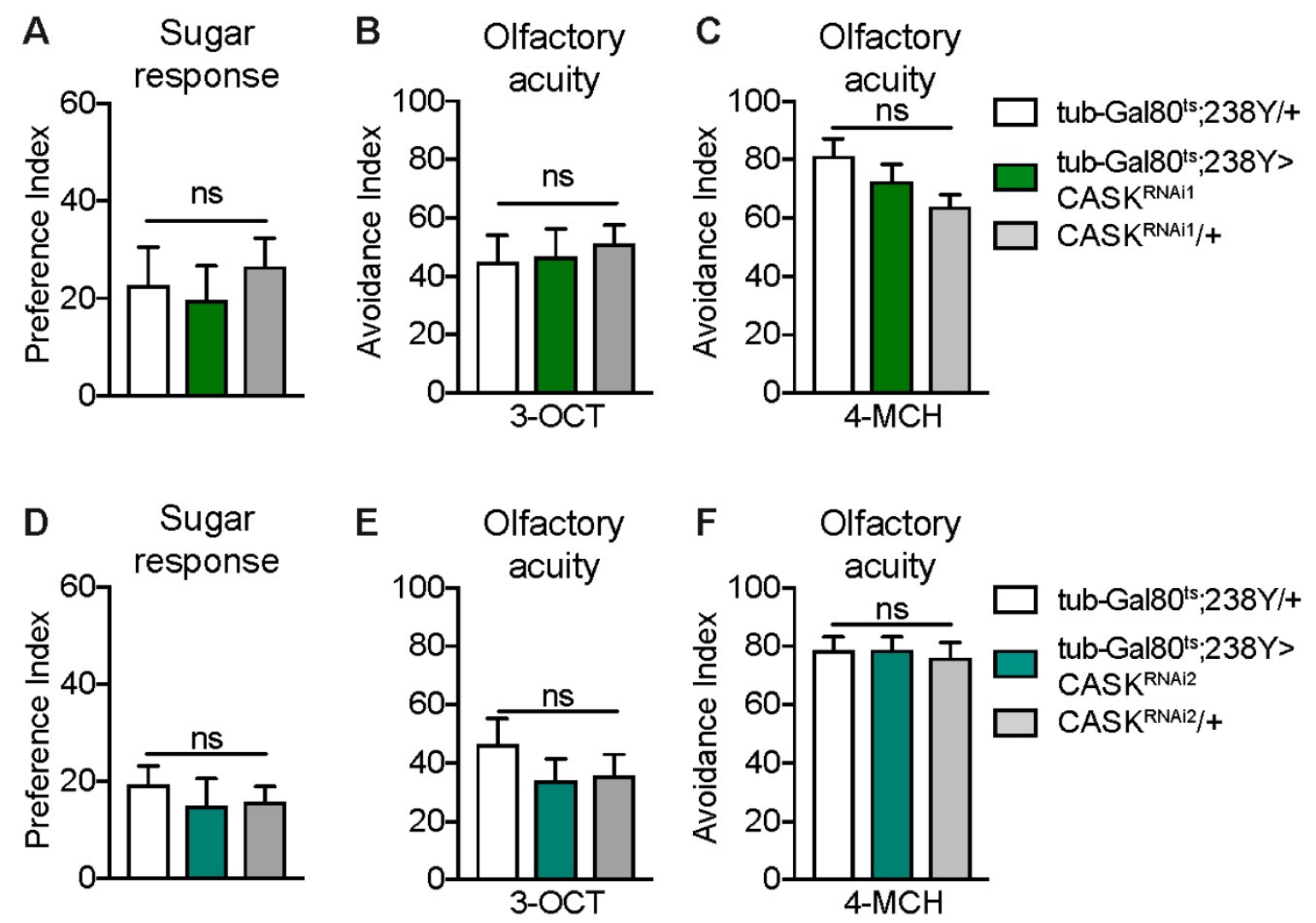

G CASK mRNA

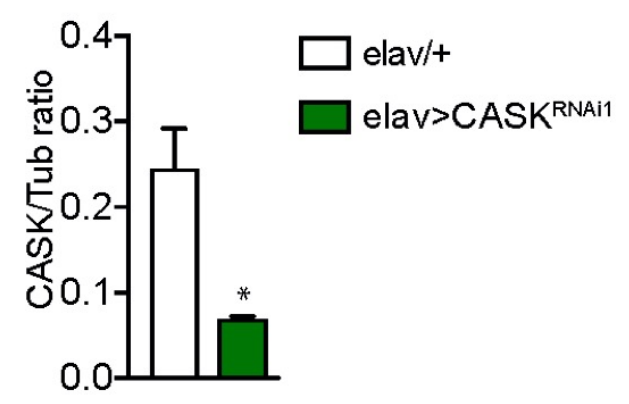

H CASK mRNA

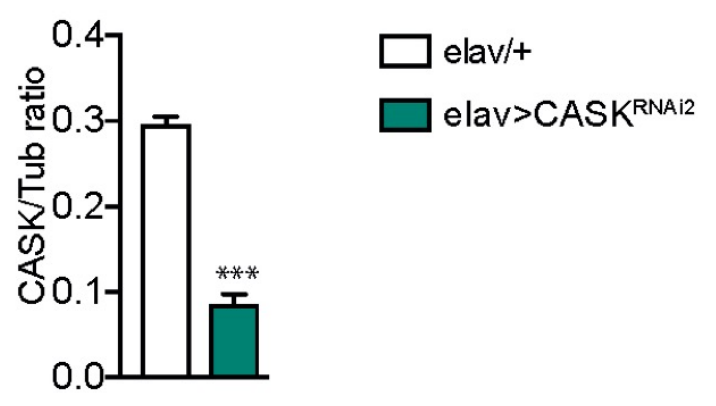

Supplementary Figure 2. CASK RNAi efficiency and sugar response and olfaction acuity in CASK knock-down condition (related to Figure 3).

$\boldsymbol{A}$, The sugar response of flies expressing $C A S K^{\text {RNAil }}$ in the adult MB under the control of tub-Gal80 $0^{\text {ts }} ; 238 Y$ driver did not differ from controls $(\mathrm{n}=14-12, \mathrm{~F}(2,37)=0.25, \mathrm{p}=0.77) . \boldsymbol{B}-\boldsymbol{C}$, Normal olfactory acuity was observed in these flies expressing $C A S K^{\text {RNAil }}$ in the adult MB exposed to either 3-octanol $(\boldsymbol{B} \mathrm{n}=8, \mathrm{~F}=(2,21)=0.15)$ or 4-methylcyclohexanol $(\boldsymbol{C}, \mathrm{n}=8$, 
$\mathrm{F}(2,21)=2.82, \mathrm{p}=0.08) . \boldsymbol{D}$, The sugar response of flies expressing $C A S K^{R N A i 2}$ in the adult MB

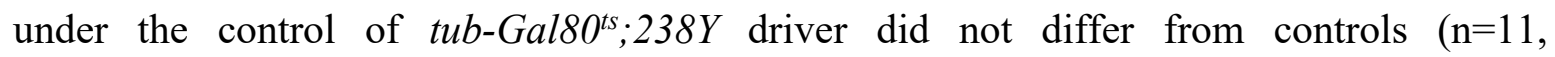
$\mathrm{F}(2,30)=0.28, \mathrm{p}=0.75) . \boldsymbol{E}-\boldsymbol{F}$, Normal olfactory acuity was observed in these flies expressing $C A S K^{\text {RNAi2 }}$ in the adult MB exposed to either 3-octanol $(\boldsymbol{E}, \mathrm{n}=10, \mathrm{~F}(2,27)=0.80, \mathrm{p}=0.45)$ or 4-methylcyclohexanol $(\boldsymbol{F}, \mathrm{n}=10, \mathrm{~F}(2,27)=0.11, \mathrm{p}=0.89)$. Data are shown as mean $\pm \mathrm{SEM}$. Statistical analyses were performed with one-way ANOVA followed by a post-hoc NewmanKeuls test (ns : not significant). $\boldsymbol{G}$, A strong reduction in CASK mRNA levels was observed in flies expressing $C A S K^{R N A i l}$ under the control of elav driver ( $\left.\mathrm{n}=3, \mathrm{t}_{4}=3.83, \mathrm{p}=0.019\right) . \boldsymbol{H}, \mathrm{A}$ strong reduction in CASK mRNA levels was observed in flies expressing $C A S K^{R N A i 2}$ under the control of elav driver $\left(\mathrm{n}=3, \mathrm{t}_{4}=15.28, \mathrm{p}=0.0001\right)$. The $\mathrm{qPCR}$ results are shown as ratios to the reference. Statistical analyses were performed with a two-tailed unpaired t-test $\left(* * \mathrm{p}<0.01,{ }^{*} \mathrm{p}<0.05\right)$. 

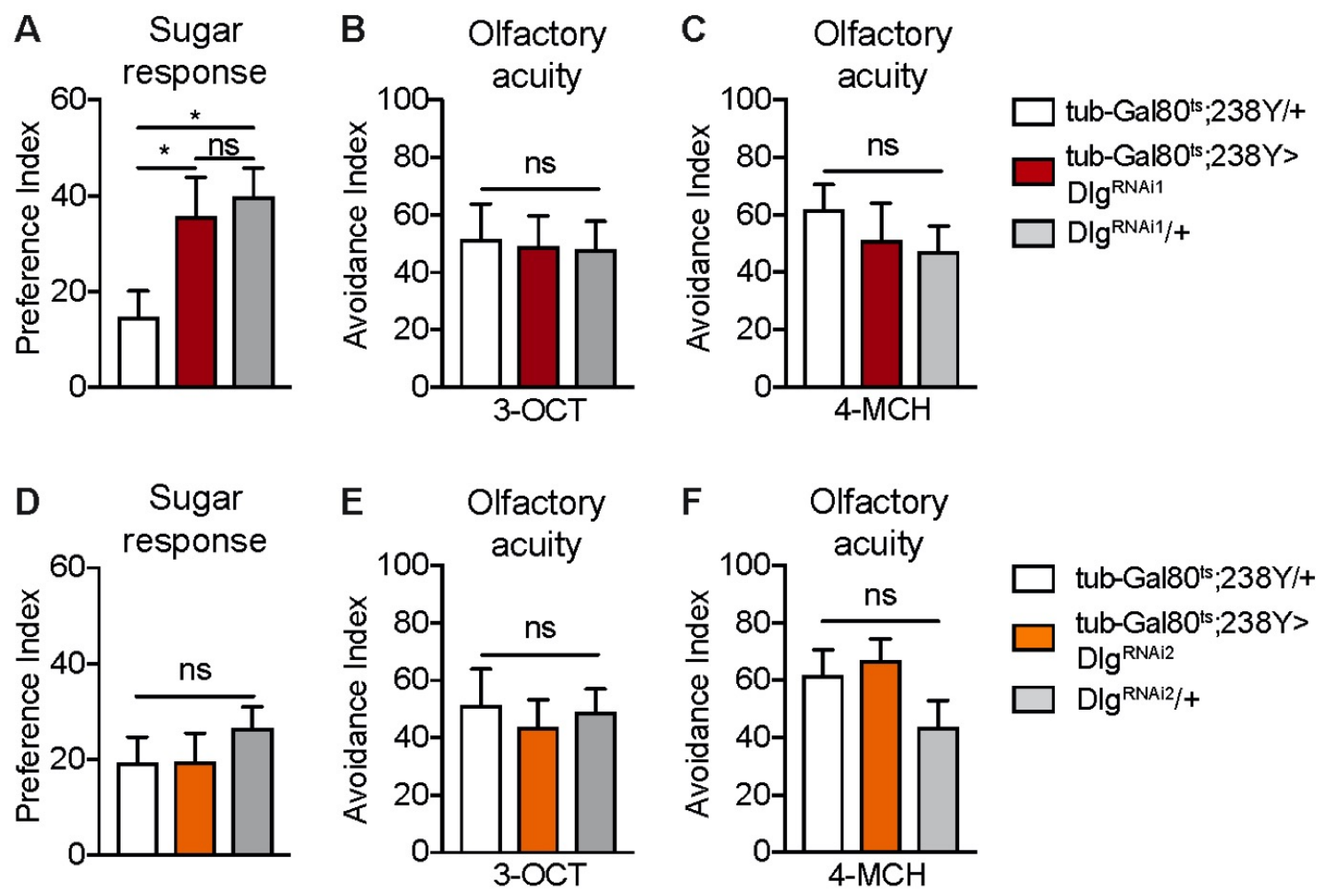

G DLG mRNA

H DLG mRNA
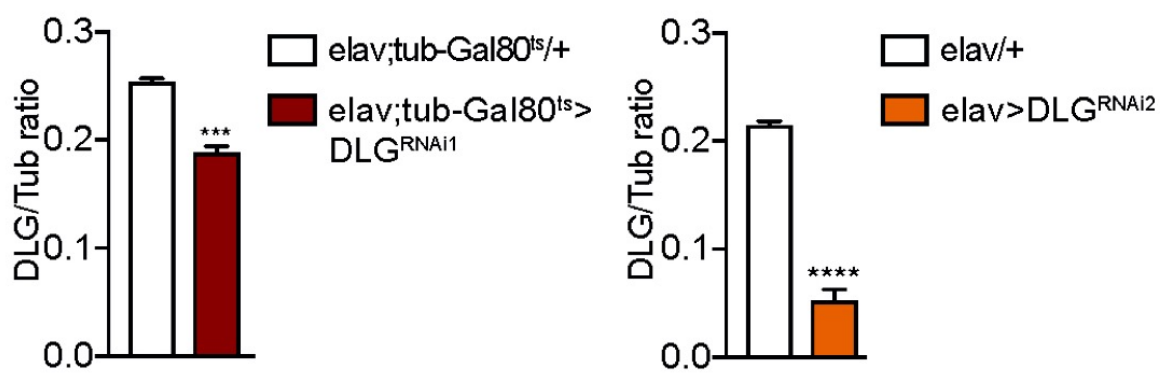

Supplementary Figure 3. Dlg RNAi efficiency and sugar response and olfaction acuity in Dlg knock-down condition (related to Figure 4).

$\boldsymbol{A}$, The sugar response of flies expressing $D \lg ^{R N A i l}$ in the adult MB under the control of $t u b$ -

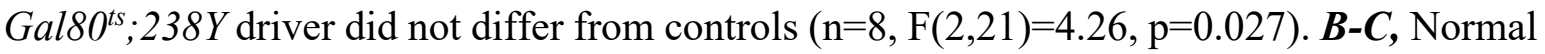
olfactory acuity was observed in these flies expressing $D l g^{R N A i l}$ in the adult MB exposed to either 3-octanol $(\boldsymbol{B}, \mathrm{n}=8, \mathrm{~F}(2,21)=0.03, \mathrm{p}=0.97)$ or 4-methylcyclohexanol $(\boldsymbol{C}, \mathrm{n}=8$, $\mathrm{F}(2,21)=0.54, \mathrm{p}=0.58) . \boldsymbol{D}$, The sugar response of flies expressing $D \lg ^{R N A i 2}$ in the adult MB 
under the control of $t u b-G a l 80^{t s} ; 238 Y$ driver did not differ from controls $(\mathrm{n}=14-13, \mathrm{~F}(2$, $38)=0.3, p=0.53) . \boldsymbol{E}-\boldsymbol{F}$, Normal olfactory acuity was observed in these flies expressing $\lg ^{R N A i 2}$ in the adult $\mathrm{MB}$ exposed to either 3-octanol $(\boldsymbol{E}, \mathrm{n}=8, \mathrm{~F}(2,21)=0.15, \mathrm{p}=0.85)$ or 4methylcyclohexanol $(\boldsymbol{F}, \mathrm{n}=8, \mathrm{~F}(2,21)=2.16, \mathrm{p}=0.13)$. Data are shown as mean $\pm \mathrm{SEM}$. Statistical analyses were performed with one-way ANOVA followed by a post-hoc NewmanKeuls test $\left({ }^{*} \mathrm{p}<0.05\right.$, ns : not significant). $\boldsymbol{G}$, When we used the elav driver to control $D \lg ^{R N A i l}$ expression, it resulted in lethality at the pupal stage. Thus, for this RNAi, we restricted $D l g^{R N A i l}$ expression to adulthood using the $t u b-G a l 80^{t s}$; elav driver. After 3 days of induction, total RNA was extracted from these flies and then processed similar to the other samples. After 3 days of induction, a reduction in Dlg mRNA levels was observed in flies expressing $D \lg ^{\text {RNAil }}$ in adult neurons under the control of tub-Gal80 ${ }^{t s}$; elav driver $\left(\mathrm{n}=3, \mathrm{t}_{4}=11.40\right.$, $\mathrm{p}=0.0003) . \boldsymbol{H}$, A strong reduction in Dlg mRNA levels was observed in flies expressing $D g^{R N A i 2}$ under the control of elav driver $\left(\mathrm{n}=3, \mathrm{t}_{4}=16.23, \mathrm{p}<0.0001\right) . \mathrm{qPCR}$ analyses are shown as ratios to the reference. Statistical analyses were performed with a two-tailed unpaired $t$ test $(* * * \mathrm{p}<0.001, * * * * \mathrm{p}<0.0001)$. 

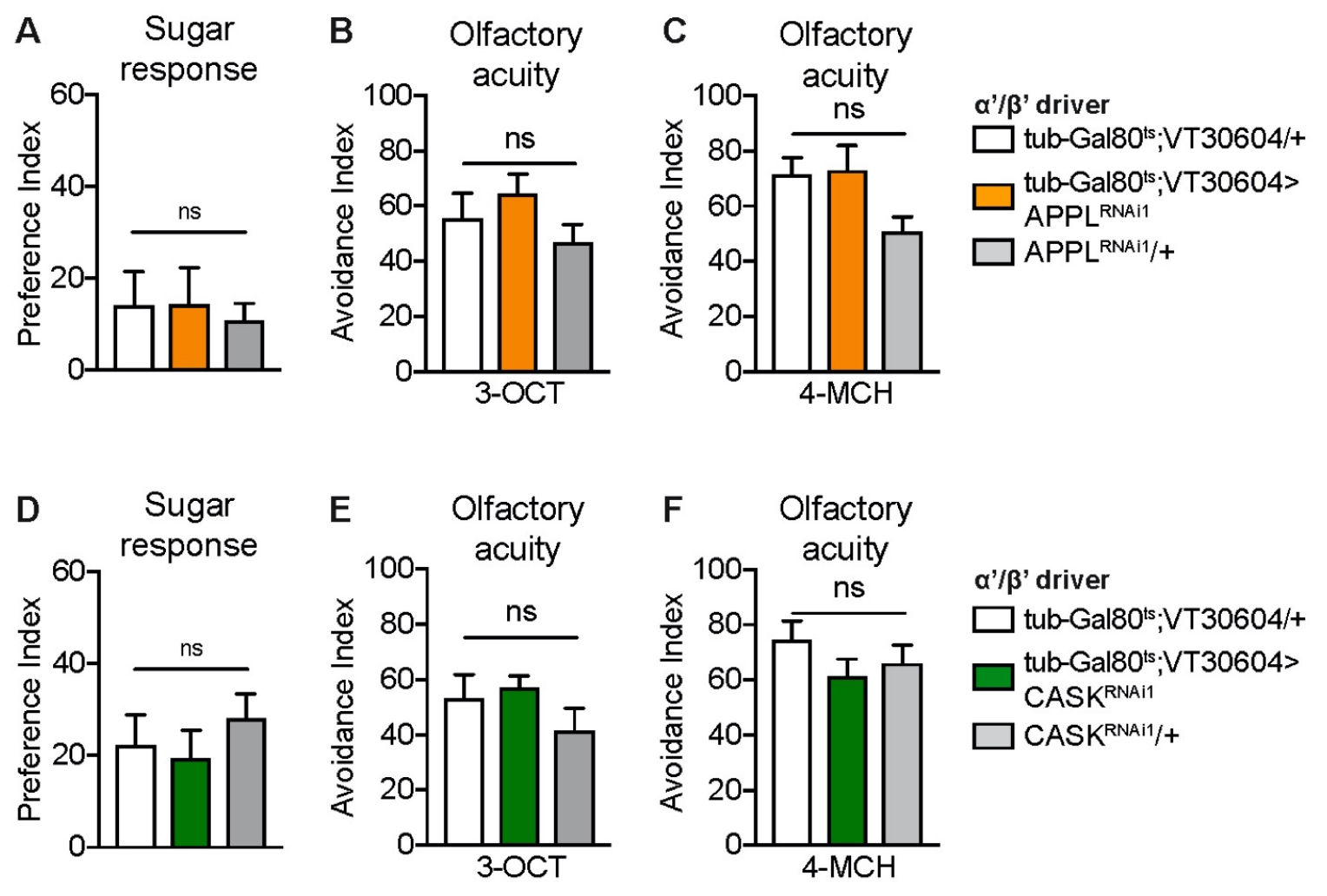

$\alpha^{\prime} / \beta^{\prime}$ driver
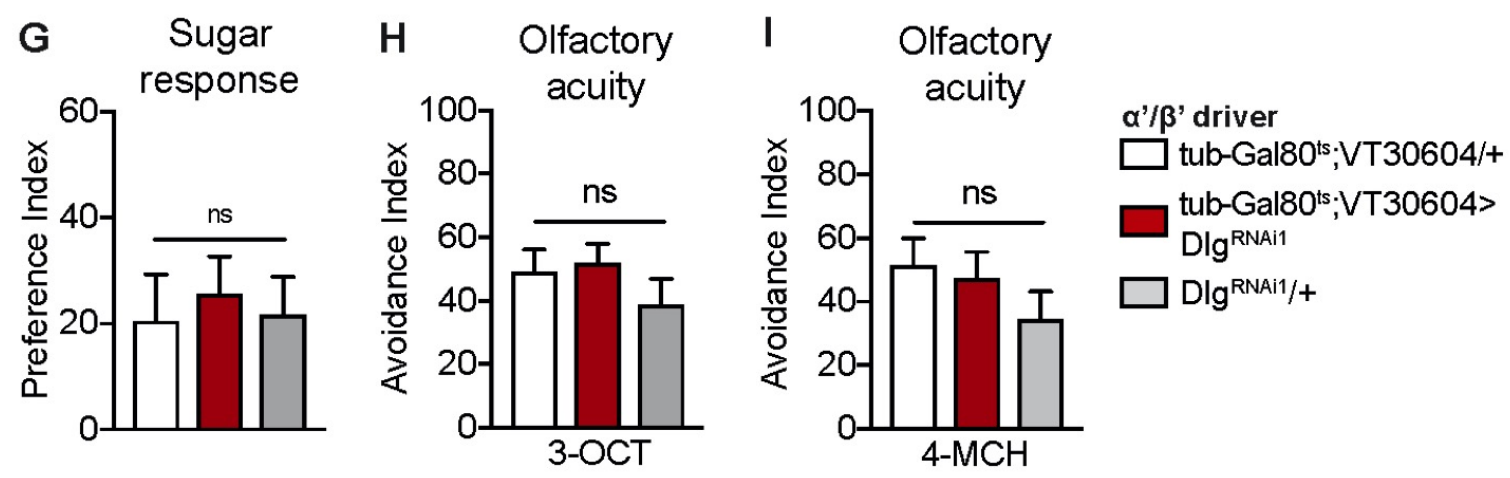

Supplementary Figure 4. Sugar responses and olfactory acuity of flies expressing APPL, CASK or DIg RNAi in adult $\alpha^{\prime} \beta$ ' MB neurons (related to Figure 5).

$A, A P P L^{R N A i l}$ expression in the adult $\alpha^{\prime} \beta^{\prime}$ neurons using the $t u b-G a l 80^{t s}$; VT30604 driver did not alter sugar responses $(\mathrm{n}=12-10, \mathrm{~F}(2,31)=0.07, \mathrm{p}=0.92) . \boldsymbol{B}-\boldsymbol{C}$ Normal olfactory acuity was observed in these flies expressing $A P P L^{R N A i l}$ in the adult $\alpha^{\prime} \beta^{\prime}$ MB exposed to either 3-octanol $(\boldsymbol{B}, \mathrm{n}=8, \mathrm{~F}(2,21)=1.44, \mathrm{p}=0.25)$ or 4-methylcyclohexanol $(\boldsymbol{C}, \mathrm{n}=8, \mathrm{~F}(2,21)=3.41, \mathrm{p}=0.052)$. D, CASK ${ }^{R N A i l}$ expression in the adult $\alpha^{\prime} \beta$ ' neurons using the $t u b-G a l 80^{t s}$; VT30604 driver did 
not alter sugar responses $(\mathrm{n}=13, \mathrm{~F}(2,36)=0.56, \mathrm{p}=0.57) . \boldsymbol{E}-\boldsymbol{F}$ Normal olfactory acuity was observed in these flies expressing $C A S K^{R N A i l}$ in the adult $\alpha^{\prime} \beta^{\prime}$ MB exposed to either 3-octanol $(\boldsymbol{E}, \mathrm{n}=11, \mathrm{~F}(2,30)=1.31, \mathrm{p}=0.28)$ or 4 -methylcyclohexanol $(\boldsymbol{F}, \mathrm{n}=11, \mathrm{~F}(2,30)=1.14, \mathrm{p}=0.33)$. $\boldsymbol{G}, D \lg ^{R N A i l}$ expression in the adult $\alpha^{\prime} \beta^{\prime}$ neurons using the $t u b-G a l 80^{t s}$; VT30604 driver did not alter sugar responses $(\mathrm{n}=13, \mathrm{~F}(2,36)=0.12, \mathrm{p}=0.88) . \boldsymbol{H}-\boldsymbol{I}$ Normal olfactory acuity was observed in these flies expressing $D \lg ^{R N A i 1}$ in the adult $\alpha^{\prime} \beta^{\prime}$ MB exposed to either 3-octanol $(\boldsymbol{H}, \mathrm{n}=8, \mathrm{~F}(2,21)=1.03, \mathrm{p}=0.37)$ or 4-methylcyclohexanol $(\boldsymbol{I}, \mathrm{n}=8, \mathrm{~F}(2,21)=1.17, \mathrm{p}=0.32)$. Data are shown as mean \pm SEM. Statistical analyses were performed with one-way ANOVA followed by a post-hoc Newman-Keuls test (ns : not significant). 
A APPL mRNA

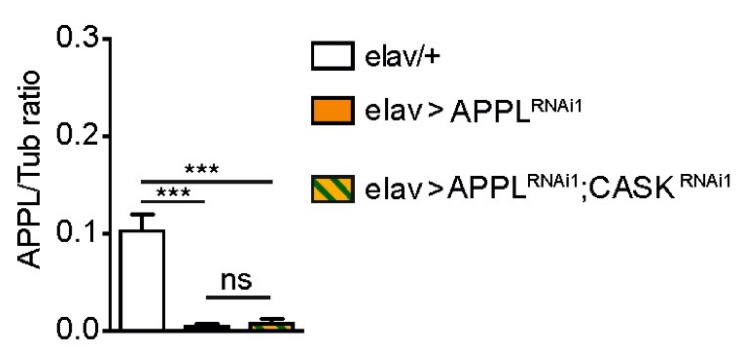

C

APPL mRNA

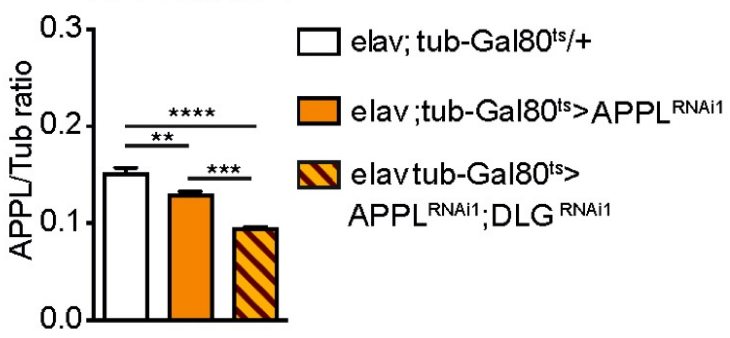

B CASK mRNA

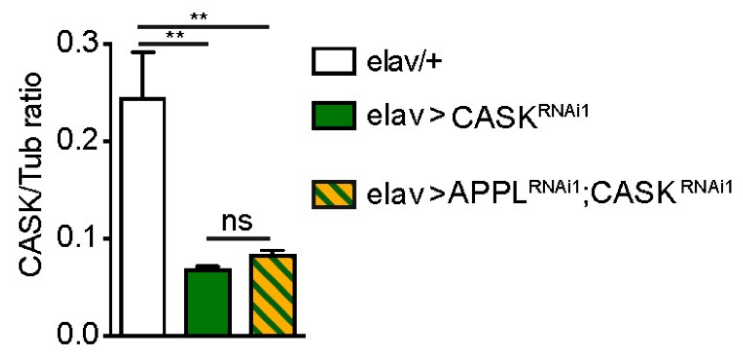

D

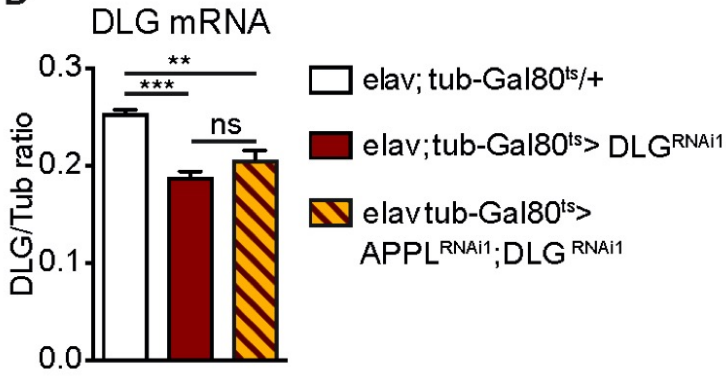

G Olfactory
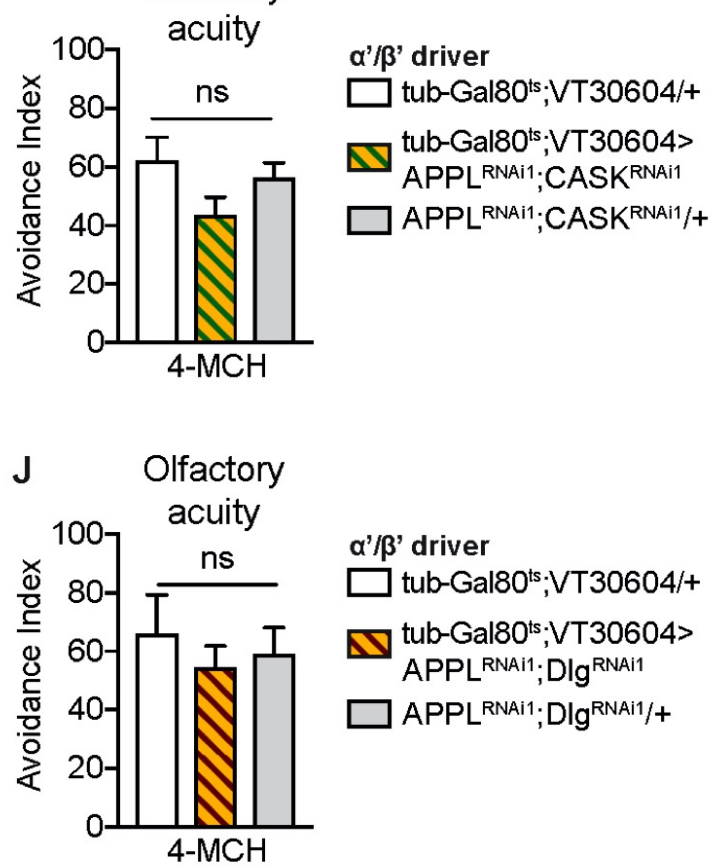

Supplementary Figure 5. RNAi efficiency in double RNAi construction flies and sugar response and olfactory acuity of flies expressing double RNAi constructs for APPL and CASK or APPL and DLG in adult $\alpha^{\prime} \beta$ ' MB neurons (related to Figure 6). 
$\boldsymbol{A}-\boldsymbol{B}$, Expression of $A P P L^{R N A i l} ; C A S K^{R N A i l}$ in neurons using the pan-neuronal driver elav resulted in a significant reduction in both APPL mRNA level $(\mathbf{A}, \mathrm{n}=3, \mathrm{~F}(2,6)=39.45$, $\mathrm{p}=0.0004)$ and CASK mRNA level $(\mathbf{B}, \mathrm{n}=3, \mathrm{~F}(2,6)=13.47)$. For both APPLmRNA and CASK mRNA, the level of reduction is not different between single or double RNAi conditions. $\boldsymbol{C}$-D After 3 days of induction, expression of $A P P L^{R N A i l} ; D g^{R N A i l}$ in adult neurons under the control of $t u b-G a l 80^{t s}$; elav driver resulted in a significant reduction in both APPL mRNA level $(\boldsymbol{C}, \mathrm{n}=3, \mathrm{~F}(2,6)=91.88, \mathrm{p}<0.0001)$ and Dlg mRNA level $(\boldsymbol{D}, \mathrm{n}=3, \mathrm{~F}(2,6)=30.82$, $\mathrm{p}=0.0007)$. For APPL mRNA, the level of reduction in the double RNAi condition (tubGal80 $^{\text {ts }} ;$ elav $\left.>A P P L^{R N A i l} ; D \lg ^{R N A i l}\right)$ is significantly stronger than in the single RNAi

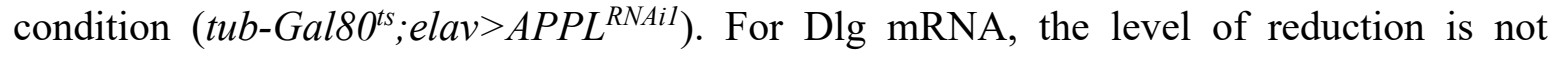
different between single $\left(t u b-G a l 80^{t s}\right.$; elav $>$ Dlg $\left.{ }^{R N A i l}\right)$ or double RNAi (tub-

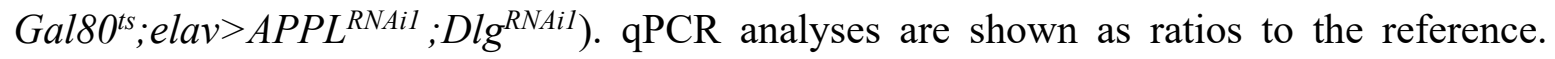
Statistical analyses were performed with one-way ANOVA followed by a post-hoc NewmanKeuls test $\left({ }^{* *} \mathrm{p}<0.01,{ }^{* * *} \mathrm{p}<0.001,{ }^{* * * *} \mathrm{p}<0.0001\right.$, ns : not significant). $\boldsymbol{E}$, After 1 day of induction, $A P P L^{R N A i l} ; C A S K^{R N A i l}$ expression in the adult $\alpha^{\prime} \beta^{\prime}$ neurons using the tubGal80 ${ }^{t s}$; VT30604 driver did not alter sugar responses $(\boldsymbol{E}, \mathrm{n}=10, \mathrm{~F}(2,27)=0.56, \mathrm{p}=0.58) . \boldsymbol{F}-\boldsymbol{G}$ After 1 day of induction, normal olfactory acuity was observed in these flies expressing $A P P L^{R N A i l} ; C A S K^{R N A i l}$ in the adult $\alpha^{\prime} \beta^{\prime}$ MB exposed to either 3 -octanol $(\boldsymbol{F}, \mathrm{n}=10$, $\mathrm{F}(2,27)=0.24, \mathrm{p}=0.78)$ or 4-methylcyclohexanol $(\boldsymbol{G}, \mathrm{n}=8, \mathrm{~F}(2,21)=2.37, \mathrm{p}=0.12) . \boldsymbol{H}$, After 1 day of induction, $A P P L^{R N A i l} ; D l g^{R N A i l}$ expression in the adult $\alpha^{\prime} \beta^{\prime}$ neurons using the $t u b$ Gal80 $^{t s} ;$ VT30604 driver did not alter sugar responses $(\mathrm{n}=12, \mathrm{~F}(2,33)=0.01, \mathrm{p}=0.99) . \boldsymbol{I}-\boldsymbol{J}$, After 1 day of induction, normal olfactory acuity was observed in these flies expressing $A P P L^{R N A i l} ; D \lg ^{R N A i l}$ in the adult $\alpha^{\prime} \beta^{\prime}$ MB exposed to either 3 -octanol $(\boldsymbol{I}, \mathrm{n}=8, \mathrm{~F}(2,21)=1.65$, $\mathrm{p}=0.21)$ or 4-methylcyclohexanol $(\boldsymbol{J}, \mathrm{n}=10, \mathrm{~F}(2,27)=0.33, \mathrm{p}=0.71)$. Data are shown as mean 
\pm SEM. Statistical analyses were performed with one-way ANOVA followed by a post-hoc Newman-Keuls test (ns : not significant).

A CASK mRNA B CASK mRNA
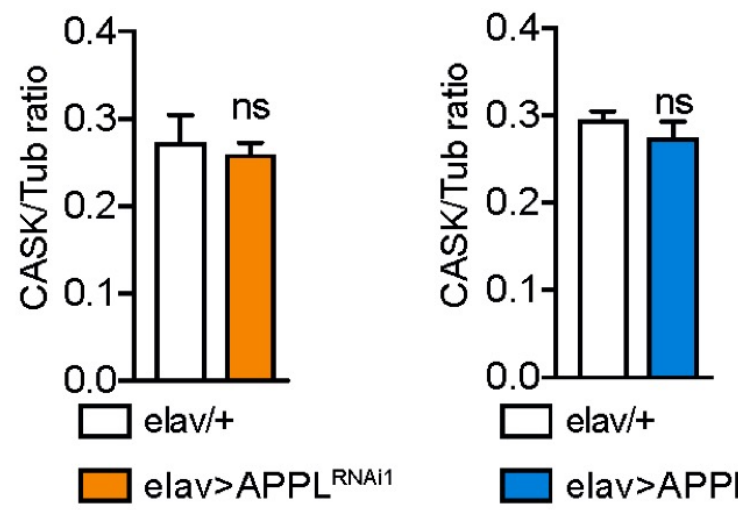

$\square$ elav>APPL ${ }^{\text {RNAi2 }}$

C

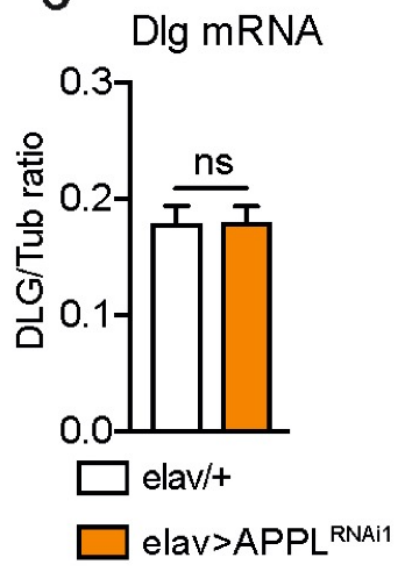

D Dlg mRNA
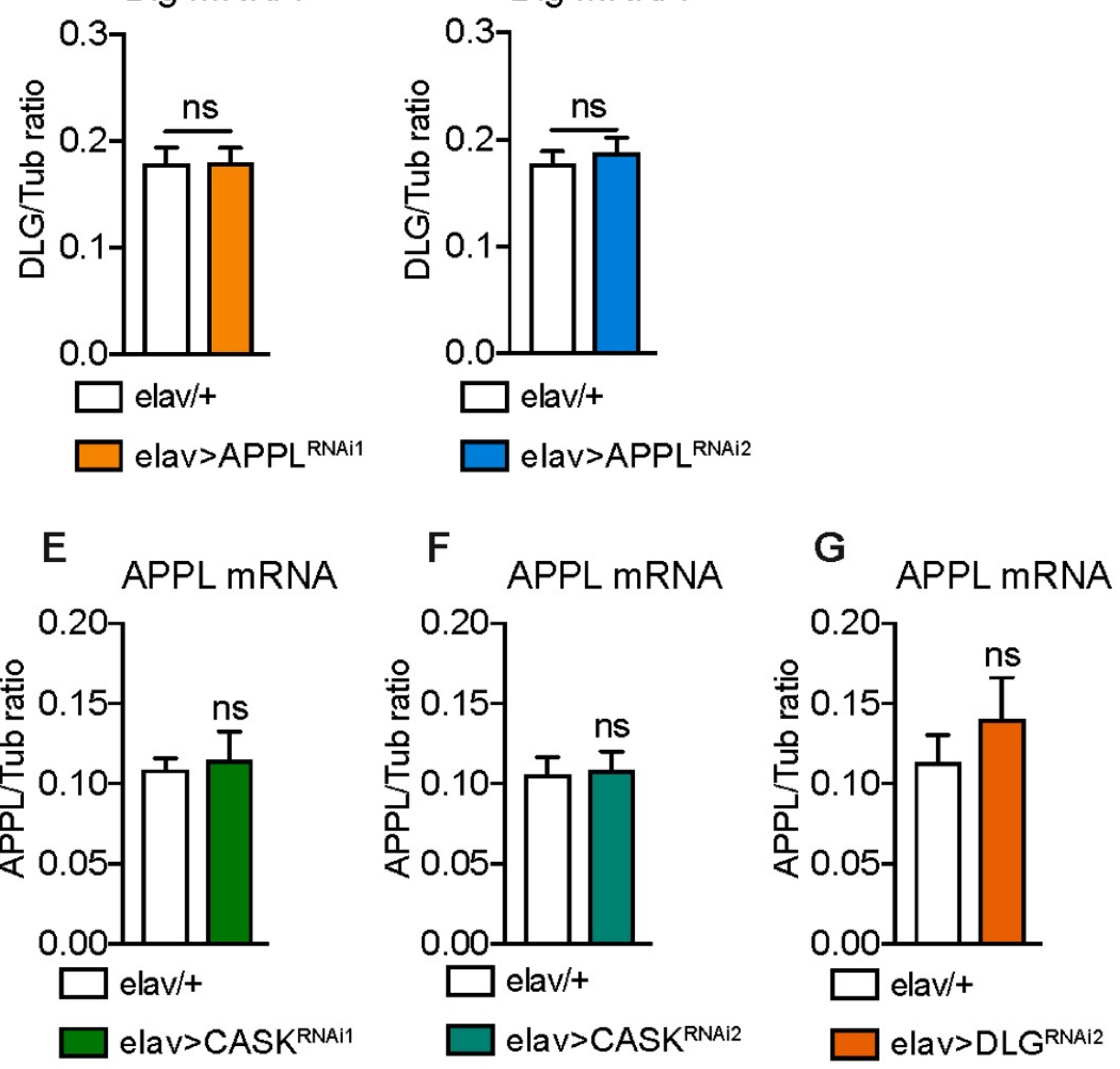
Supplementary Figure 6. mRNA expression level of CASK, DIg and APPL in response to the downregulated expression of their interaction partners (related to Figure 6).

$\boldsymbol{A}-\boldsymbol{B}$, mRNA level of CASK in the Drosophila brain is not affected by downregulation of $A P P L$ using the elav driver with either $A P P L^{R N A i l}\left(\boldsymbol{A}, \mathrm{n}=3, \mathrm{t}_{4}=0.41, \mathrm{p}=0.69\right)$ or $A P P L^{R N A i 2}(\boldsymbol{B}$, $\left.\mathrm{n}=3, \mathrm{t}_{4}=1.014, \mathrm{p}=0.37\right) . \boldsymbol{C}-\boldsymbol{D}$, Similarly, mRNA level of Dlg in the Drosophila brain is not affected by downregulation of $A P P L$ using the elav driver with either $A P P L^{R N A i l}(\boldsymbol{C}, \mathrm{n}=3$, $\left.\mathrm{t}_{4}=0.01, \mathrm{p}=0.99\right)$ or $A P P L^{R N A i 2}\left(\boldsymbol{D}, \mathrm{n}=3, \mathrm{t}_{4}=0.59, \mathrm{p}=0.59\right) . \boldsymbol{E}-\boldsymbol{F}$, mRNA level of APPL in the Drosophila brain is not affected by downregulation of $C A S K$ using the elav driver with either $\operatorname{CASK}^{R N A i 1}(\boldsymbol{E}, \mathrm{n}=3, \mathrm{t} 4=0.31, \mathrm{p}=0.77)$ or $\operatorname{CASK}^{R N A i 2}(\boldsymbol{F}, \mathrm{n}=3, \mathrm{t} 4=0.20, \mathrm{p}=0.85) . \mathrm{G}$, Similarly, mRNA level of APPL in the Drosophila brain is not affected by downregulation of Dlg using the elav driver with $\operatorname{Dlg}^{R N A i 2}(\mathrm{n}=3, \mathrm{t} 4=0.89, \mathrm{p}=0.42)$ flies. $\mathrm{qPCR}$ analyses are shown as ratios to the reference. Data are shown as mean \pm SEM. Statistical analyses were performed with unpaired t-test (ns : not significant). 